Pre-publication version. Please refer to the published version when citing: Journal of Linguistics / FirstView Article / August 2015, pp 1 - 43 DOI:

10.1017/S0022226715000298, Published online: 14 August 2015

\title{
Structure building and thematic constraints in Bantu inversion constructions ${ }^{1}$
}

\author{
LUTZ MARTEN \& HANNAH GIBSON
}

SOAS, University of London

(Received 2 January 2014; revised 17 July 2015)

Bantu inversion constructions include locative inversion, patient inversion (also called subject-object reversal), semantic locative inversion and instrument inversion. The

\footnotetext{
${ }^{1}$ Earlier versions of this paper were presented at Groningen University, King's College London, Leiden University, Oxford University, Queen Mary University of London,
} SOAS, Tsinghua University and ZAS Berlin, and we are grateful to audiences at these events for helpful comments and suggestions, as well as to Ronie Cann, Mary Dalrymple, Yussuf Hamad, Jekura Kavari, Ruth Kempson, Nancy Kula, Wenshan Li, Chris Lucas, Thilo Schadeberg, Jenneke van der Wal, Jochen Zeller and three anonymous Journal of Linguistics referees. We are especially grateful to Yussuf Hamad and Jekura Kavari for discussion of data from Swahili and Otjiherero, respectively. Parts of the research reported in this paper were supported by funding from a British Academy Small Research Grant for fieldwork in Namibia, a British Academy Network Grant for Language and Linguistic Studies of Southern African Languages, Leverhulme Trust Grant RPG-2014-208 'Morphosyntactic variation in Bantu' (Lutz Marten) and a British Academy Postdoctoral Fellowship (Hannah Gibson), which is hereby gratefully acknowledged. 
constructions show a high level of cross-linguistic variation, but also a core of invariant shared morphosyntactic and information structural properties. These include: that the preverbal position is filled by a non-agent NP triggering verbal agreement, that the agent follows the verb obligatorily, that object marking is disallowed, and that the preverbal NP is more topical, and the postverbal NP more focal. While previous analyses have tended to concentrate on one inversion type, the present paper develops a uniform analysis of Bantu inversion constructions. Adopting a Dynamic Syntax perspective, we show how the constructions share basic aspects of structure building and semantic representation. In our analysis, cross-linguistic differences in the distribution of inversion constructions result from unrelated parameters of variation, as well as from thematic constraints related to the thematic hierarchy. With some modification, the analysis can also be extended to passives.

\section{INTRODUCTION}

Bantu languages are well known for their complex verbal agreement systems, where subject, primary object and, in some languages, secondary objects can be indexed on the verb, and for the close relationship between agreement and word order (Bresnan \& Mchombo 1987). Locative inversion and patient inversion (also known as subjectobject reversal) ${ }^{2}$ are two constructions which illustrate the close relation between agreement and word order in Bantu. Both have received considerable attention in the

\footnotetext{
${ }^{2}$ As we will show, Bantu inversion constructions differ in terms of thematic restrictions rather than grammatical function, and so we use 'patient inversion' here, following Marten \& van der Wal (2014).
} 
literature (e.g. Bresnan \& Kanerva 1989; Morimoto 2000, 2006; Henderson 2006, 2011; Marten 2006). Early analyses of patient inversion highlighted the relation between the construction and passives (e.g. Givón 1979), although subsequent analyses have tended to see the two constructions as distinct (e.g. Henderson 2011). Similarly, although locative inversion and patient inversion share a number of common characteristics, many contemporary analyses do not develop a unified analysis of the two (e.g. Morimoto 2000, Hamlaoui \& Makasso 2013, although see e.g. Demuth \& Harford 1999). More recently, semantic locative inversion (Buell 2007) and instrument inversion (Zeller 2012a, 2013) have been analysed as further instances of Bantu inversion constructions, although these too have tended to be seen as separate constructions (see Marten 2014). In a comparative study of Bantu inversion constructions, Marten \& van der Wal (2014) note the structural similarities between different inversion constructions, while also charting the cross-linguistic variation found in their distribution across the language family.

The current paper develops a formal analysis of Bantu inversion constructions which is based on the broad structural similarity of the construction types and reflects the findings of Marten \& van der Wal (2014). We show that there is a shared structural core of inversion constructions in terms of how their semantic representation is established, and that their information structure follows from the structural choices made in the parsing process. We further attribute cross-linguistic variation to language-specific thematic constraints. The analysis is formulated in Dynamic Syntax (DS, Kempson, Meyer-Viol \& Gabbay 2001, Cann, Kempson \& Marten 2005), a formal model of syntax which pays specific attention to the dynamic, left-to-right development of semantic representations from words encountered in context. 
The paper is organised as follows: Section 2 provides an overview of Bantu inversion constructions, while Section 3 summarises relevant previous work. Section 4 sets out the tools of the DS framework which will be employed for our analysis. Section 5 provides a detailed account of inversion constructions and their form, information structure and thematic constraints. Section 6 discusses the possible extension of the analysis to passives, and Section 7 presents a summary and conclusions.

\section{INVERSION CONSTRUCTIONS IN BANTU: AN OVERVIEW}

Bantu inversion constructions have long been a central topic in Bantu linguistics. ${ }^{3}$ Two well-known types of inversion construction are locative inversion and patient inversion, for which several formal analyses have been proposed. In locative inversion constructions, a locative phrase precedes the verb and the logical subject (or agent) is expressed by an NP immediately following the verb. The locative phrase is marked by dedicated noun class morphology (conventionally referred to as classes 16, 17, and 18) and the subject marker agrees in locative noun class with the nominal phrase (e.g. Bresnan \& Kanerva 1989, Demuth \& Mmusi 1997, Marten 2006, Khumalo 2010, Salzmann 2011): ${ }^{4}$

\footnotetext{
${ }^{3}$ Inversion constructions are found in the vast majority of Bantu languages although there is variation as to the particular construction(s) found in a given language (see Marten \& van der Wal 2014). Bantu languages without any inversion constructions include the Northwestern Bantu languages Basaa (Hamlaoui \& Makasso 2013, 2015) and Mbuun (Bostoen \& Mundeke 2011, 2012).

${ }^{4}$ Glossing conventions follow the Leipzig Glossing Rules with the following additional abbreviations: $1,2,3$, etc.$=$ noun class number; $1 \mathrm{st}=$ first person; $\mathrm{APPL}=$ applicative;
} 

(1) M-nándà mù-wéléngél-à Kàtíshà. (Nsenga)
18-9.house SM18-read-FV 1.Katisha
'In the house Katisha is reading.'

(Marten, Kula \& Thwala 2007: 227)

In patient inversion, the logical object or patient argument precedes the verb, triggering agreement on the verb, while the logical subject immediately follows the verb:

(2) Ici-ya ci-tul-a imw-ana. (Luguru)
7-pot SM7-break-FV 1-child
'The child broke the pot.' (lit.: 'The pot broke the child.')

(Mkude 1974: 133)

In both construction types, the logical subject follows the verb, while the preverbal position is occupied by a locative or patient NP which shows agreement with the verb. Other inversion constructions attested in Bantu include semantic locative inversion (3), instrument inversion (4) and complement inversion (5):

$\mathrm{CC}=$ complement case $; \mathrm{CJ}=$ conjoint $; \mathrm{DC}=$ default case $; \mathrm{DJ}=$ disjoint $; \mathrm{FUT}=$ future $; \mathrm{FV}$ $=$ final vowel $; \mathrm{HAB}=$ habitual $; \mathrm{LOC}=$ locative $; \mathrm{OM}=$ object marker; $\mathrm{PASS}=$ passive $; \mathrm{PRF}$ $=$ perfective $; \mathrm{PROCL}=$ pronominal clitic $; \mathrm{PST}=$ past $\mathrm{SM}=$ subject marker. 
(3) I-khishi li-phek-el-a u-mama. (Zulu)

5-kitchen SM5-cook-APPL-FV 1a-mother

'Mother is cooking in the kitchen.'

(Zeller 2013: 1111)

(4) Isi-punu si-dl-a u-John. (Zulu)

7-spoon SM7-eat-FV 1a-John

'John is using the spoon to eat.'

(Zeller 2012a: 134)

(5) Gu-kina gu-kuunda aba-ana. (Kinyarwanda)

15-play SM15-like 2-child

'It is the children who like to play.' (lit.: 'Playing likes the children.')

(Morimoto 2000: 183)

We discuss specific details of inversion constructions in the following sections.

However, here we provide a more general illustration of four common characteristics, based on Marten \& van der Wal (2014).

In locative inversion, while the locative phrase can be postposed, as in (6b), or omitted, as in (6c), the postverbal agent NP has to immediately follow the verb, as seen in $(6 \mathrm{c}, \mathrm{d})$ :

(6) (a) M-mi-têngo mw-a-khal-a a-nyăni. (Chichewa)

18-4-tree SM18-PRF-sit-FV 2-baboon

'In the trees are sitting baboons.'

(b) Mw-a-khal-a a-nyăni m-mi-têngo.

SM18-PRF-sit-FV 2-baboon 18-4-tree

'In the trees are sitting baboons.' 
(c) Mw-a-khal-á mí-kângo.

SM18-PRF-remain-FV 4-lion

'There (inside some place) have remained lions.'

(d) *Mw-a-khal-a m-mi-têngo a-nyăni.

SM18-PRF-sit-FV 18-4-tree 2-baboon

Intended: 'In the trees are sitting baboons'

(Bresnan \& Kanerva 1989: 3, 4, 11)

That the postverbal NP cannot be omitted is shown in ( $7 b)$, from Otjiherero:

(a) M-òn-djúwó mw-á hìtí é-rùngà. (Otjiherero)

18-9-house SM18-PST enter 5-thief

'The thief entered the house.' ('Into the house entered a/the thief.')

(Möhlig, Marten \& Kavari 2002: 102)

(b) *M-òn-djúwó mw-á hìtí

18-9-house SM18-PST enter

(adapted from Marten 2006: 111)

Thus, while the logical subject immediately follows the verb, and cannot be omitted, a locative (or instrument or patient) phrase precedes the verb, triggering agreement.

In terms of information structure, the preverbal phrase is often topical, representing old information or a background or scene-setting topic, whilst the postverbal NP can encode focus and be associated with new information. Alternatively, inversion constructions may function as thetic statements, where the whole proposition is focused 
and often expresses a remarkable or unexpected event. ${ }^{5}$ For example, Mkude (1974: 133) notes, with respect to Luguru, that a non-inverted sentence like (8) is a good answer to questions like 'What happened?', 'What did the child do?' or 'What did the child break?':
(8) Imw-ana ka-tul-a ici-ya. (Luguru)
1-child SM1-break-FV 7-pot
'The child broke the pot.'

(Mkude 1974: 133)

In contrast, a patient inversion construction such as (9) is a good answer to 'Who broke the pot?' or 'The pot, who broke it?', where the logical subject provides new information:

(9) Ici-ya ci-tul-a imw-ana. (Luguru)
7-pot SM7-break-FV 1-child
'The child broke the pot.' (lit.: 'The pot broke the child.')

(Mkude 1974: 133)

\footnotetext{
${ }^{5}$ The terms 'topic' and 'focus' have been the subject of significant debate (see, among others, Halliday 1967, Vallduví 1992, Lambrecht 1994, É. Kiss 1998, Sasse 2006, Krifka 2007, Matić \& Wedgwood 2013). We make no broader claims with regard to the appropriateness of one approach to information structure over another. However, for the purposes of this paper, we broadly consider topic to be associated with given or known information and focus to be associated with new information.
} 
In locative inversion, the postverbal NP can attract new information focus - hosting a wh-pronoun, often inherently focussed, as in (10), as well as supplying the value in the answer (compare (7a) above):

$\begin{array}{lll}\text { (10) Mò-n-gàndá mw-á } & \text { hìtí ùné? (Otjiherero) } \\ \text { 18-9-house } & \text { SM18-PST enter who }\end{array}$

'Who entered the house?' (Marten, field notes)

Locative inversion in Tswana can be used for presentational focus, resulting in a focus reading on the postverbal NP or on the proposition, as in (11).

(11) Gó pél-á bà-sádì.
SM17 sing-FV 2-woman
'There are women singing.'

(Tswana)

(Creissels 2011: 42)

Patient inversion in Swahili, shown in the next two examples, can give rise to 'counterexpectational' interpretations. In (12) the climbing of the hill is remarkable: Whiteley \& Mganga (1969: 115) provide as a context a situation where walking on the hill was tabooed, but some foreigners, unaware of the taboo, were climbing it. In (13) singing the song constitutes the remarkable event: 'The whole ceremony is being praised' (Whiteley \& Mganga 1969: 113). 
(12) M-lima u-me-pand-a wa-tu. (Swahili)

3-hill SM3-PRF-climb-FV 2-person

'People have climbed the hill.' (lit.: 'The hill has climbed the people.')

(Whiteley \& Mganga 1969: 115)

(13) Wimbo u-ta-imb-a wa-tu mia. (Swahili)

11-song SM11-FUT-sing-FV 2-person hundred

'A hundred people will sing the song.'

(Whiteley \& Mganga 1969: 113)

A further quality of inversion constructions is that object marking is not permitted:

$(14)$

*M-on-djuwo mw-a ri hiti (Otjiherero)

18-9-house SM18-PST OM5 enter

Intended: 'He/she entered the house'

(Marten, field notes)

(15) *Cyi-(ra)-ba-som-a

(Kinyarwanda)

SM7-DJ-OM2-read-FV

Intended: 'They are reading it'

(Morimoto 2006: 169)

This restriction affects preverbal object markers, but is not a ban on pronominalisation as such, since postverbal pronominal object clitics are permissible, as (16) shows. 
(16) M-òn-djúwó mw-á hìtí rò.

(Otjiherero)

18-9-house SM18-PST enter PROCL5

'He/she (i.e. the thief) entered the house.'

(Marten, field notes)

Finally, inversion constructions are often associated with morphological or prosodic cues which indicate a close relation between the verb and the postverbal NP. In Chichewa, for example, illustrated in (17), the postverbal NP is phrased together with the verb, indicated by the absence of lengthening of the penultimate vowel which occurs before prosodic phrase boundaries.
(17) (a) (Ku-muudzi) (ku-na-bwér-á a-lendó átáàtu). (Chichewa)
17-3.village SM17-PST-come-FV 2-visitor three
'To the village came three visitors.'
(b) *(Ku-muudzi) (ku-na-bwéèr-a) (a-lendó átáàtu)
17-3.village SM17-PST-come-FV 2-visitor three
Intended: 'To the village came three visitors'

(Bresnan \& Kanerva 1989: 9)

In Otjiherero, illustrated in (18), the postverbal NP receives tonal marking as 'complement case' (CC) rather than 'default case' (DC), similar to objects but unlike post-posed subjects (see Kavari, Marten \& van der Wal 2012). 
(18) (a) M-òn-djúwó mw-á hìtí é-rùngà. (Otjiherero)

18-9-house SM18-PST enter 5-thief.CC

'The thief entered the house.'

(b) *M-òn-djúwó mw-á hìtí è-rúngá

18-9-house SM18-PST enter 5-thief.DC

Intended: 'The thief entered the house.'

(Marten, field notes)

In patient inversion in Kirundi, in (19), the verb is in the conjoint form, which is used when the verb is followed by an object, for example, rather than in the disjoint form, which is used when the verb is final in the relevant domain.
Ama-tá y-Ø-á-nyôye
abâna.
(Kirundi)
6-milk SM6-CJ-PST-drink.PFV 2.children

'Children drank milk.'

(Ndayiragije 1999: 400)

The morphological and prosodic facts show that the postverbal NP is in a close relation with the verb, similar to the relation between verb and direct object, rather than being right-dislocated, which would result in different marking. This correlates with the fact that the postverbal NP cannot be omitted or separated from the verb, and that it is focal rather than topical. The common characteristics shared by inversion constructions are therefore: (i) the obligatory presence of the postverbal agent; (ii) absence of object marking; (iii) pragmatically, the background/topical status of the preverbal NP and the new/focal status of the postverbal NP; and (iv) the close morphological or phonological bond between the verb and the postverbal NP (see Marten \& van der Wal 2014). 


\section{PREVIOUS ANALYSES}

Early analyses of Bantu inversion constructions, such as Bokamba (1976, 1979, 1985), Givón (1979) and Kimenyi (1980), emphasised their similarity (as well as the similarity with passives), assuming that all involve advancement of a non-subject to subject position. Subsequent analyses have tended to address different constructions in isolation, focussing on specific structural, semantic and pragmatic aspects (see Marten 2014).

\subsection{Locative inversion}

Locative inversion is well described and analysed (see the summary in Salzmann 2011). Bresnan \& Kanerva (1989) develop a Lexical Functional Grammar (LFG) analysis of locative inversion in Chichewa, which involves an alternative lexical mapping between thematic role and grammatical function licensed by a rule of 'special subject default'. Under this account, a locative argument is morpho-lexically assigned the subject role, rather than the oblique role, in contexts where the other lexical argument is a theme argument (locative inversion in Chichewa is argued to be restricted to unaccusative verbs whose highest thematic role is theme). The remaining theme argument is assigned a focus feature, so that the locative phrase becomes the subject of the construction, and the postverbal logical subject is focussed. The analysis is developed further by Demuth \& Mmusi (1997), who show that in Tswana, locative inversion is possible not only with unaccusative predicates but also with unergative and passivised transitive verbs. This means that the 'special subject default' can apply even in the presence of an agent role (in unergatives), and is only disallowed when both agent and theme are present (in Tswana, transitive verbs do not show locative inversion). Subsequent research has 
shown further variation in thematic restrictions across Bantu, with Otjiherero (Marten 2006) and Ndebele (Khumalo 2010), for example, also allowing transitive verbs to undergo locative inversion (in thematic terms, in the presence of both agent and theme). This work has shown that thematic restrictions on predicates participating in locative inversion are at the heart of variation in locative inversion in Bantu.

It has also been argued that there is another parameter of variation in locative inversion: In some Bantu languages, such as Tswana and Sesotho, preverbal NPs have been shown to have (syntactic) topic properties rather than subject properties (Demuth 1990, Zerbian 2006, Marten 2011). It is sometimes proposed that because of this, inversion constructions in these languages are actually expletive constructions, and so differ from those in, for example, Chichewa (Buell 2007, Creissels 2011). The main motivation for this analysis is the absence of full agreement between the locative phrase and the verb, which shows instead default agreement, and in some cases, other characteristics of topics rather than subjects have been proposed to be relevant. However, we believe that the two aspects - presence of locative inversion and topic vs. subject - are not related to each other, even though they interact. This is because thematic restrictions obtain in languages with subjects, as well as those with topics, as can be seen in the summary of locative inversion in Table 1. 


\begin{tabular}{|c|c|c|c|c|c|c|c|}
\hline 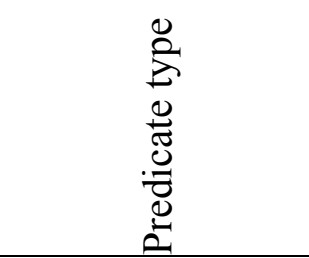 & $\begin{array}{l}01 \\
0 \\
\frac{\pi}{3} \\
\tilde{0} \\
0\end{array}$ & 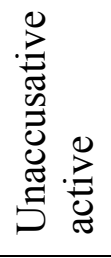 & 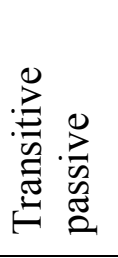 & 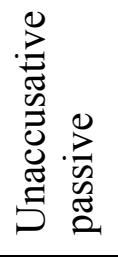 & 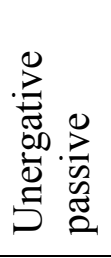 & 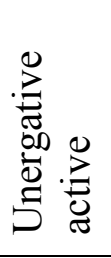 & 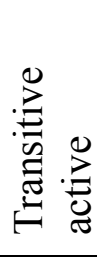 \\
\hline CiLubà & $\mathrm{OK}$ & $*$ & $*$ & $*$ & $*$ & $*$ & $*$ \\
\hline Chaga, Chichewa & $\mathrm{OK}$ & $\mathrm{OK}$ & OK & $*$ & $*$ & $*$ & $*$ \\
\hline Shona & $\mathrm{OK}$ & OK & $\mathrm{OK}$ & OK & OK & $*$ & $*$ \\
\hline Sesotho, Tswana & OK & $\mathrm{OK}$ & OK & OK & OK & OK & $*$ \\
\hline $\begin{array}{l}\text { Ndebele, } \\
\text { Otjiherero }\end{array}$ & OK & OK & OK & OK & $\mathrm{OK}$ & OK & OK \\
\hline
\end{tabular}

Table 1

Locative inversion variation with respect to predicate type

(Marten 2014: 153; Marten \& van der Wal 2014: 326).

In languages such as CiLubà, locative inversion is only found with copulas, while at the other end of the spectrum, in Ndebele and Otjiherero, locative inversion is found with transitive verbs. The distribution shows the independence of inversion and the coding of subjects/topics: Sesotho, Tswana and Ndebele are languages in which preverbal NPs are always topics, yet they show different thematic restrictions. This independence is important for our analysis and we will return to it in Section 5.

\subsection{Patient inversion}

There are also several analyses of patient inversion. As noted above, Givón (1979) proposes that patient inversion is similar to passives, in that it involves a change of grammatical function of the argument NPs, plus topicalisation of the subject. Similar analyses in terms of grammatical function change include Bokamba $(1976,1979,1985)$, Kimenyi (1980) and Russell (1985). However, subsequent work has not drawn a parallel between passives and patient inversion, based on the differences in the two 
constructions in terms of overt morphology (there is no overt marking of patient inversion comparable to the passive marker), marking of the logical subject as oblique (there is no preposition marking the postverbal NP in patient inversion), and differences in cross-linguistic distribution (a vast majority of Bantu languages have formal passives, but only a subset have patient inversion). It has also been suggested that passives and patient inversion are different because they may co-exist in a given language, without one being used as an alternative to the other (Henderson 2011: 743). It has also been argued that the preverbal NP in patient inversion constructions is not a subject but a topic (Morimoto 2000, 2006) and thus differs from the subject in passives and (some instances of) locative inversion.

However, it is clear from this list that the differences between passives and patient inversion hold more or less for the differences between passives and locative inversion, which in turn supports the view that these two inversion constructions are similar in structural terms. The three main differences between locative inversion and patient inversion which have been proposed in the literature are firstly, the difference in crosslinguistic distribution (e.g. Marten \& van der Wal 2014), secondly, under some analyses, the structural difference between the preverbal NPs in the two constructions (e.g. Morimoto 2000), and thirdly, differences in syntactic restrictions between locative and patient inversion, for example that patient inversion is - as far as we know at present - not possible with transitive verbs (e.g. Kimenyi 1980). We will return to these points in the subsequent discussion.

Among generative approaches, patient inversion is often analysed as the movement of the object to some functional projection usually reserved for the subject, and subsequent verb raising. Kinyalolo (1991) proposes that the object moves to Spec-IP, 
while Ura (2000) and Ndayiragije (1999) propose that it moves to Spec-TP. Henderson (2011) proposes that the object moves to a Topic position above TP, illustrated in (20), reflecting its information structure status.

(20) Patient inversion with TOP feature (Henderson 2011: 746)

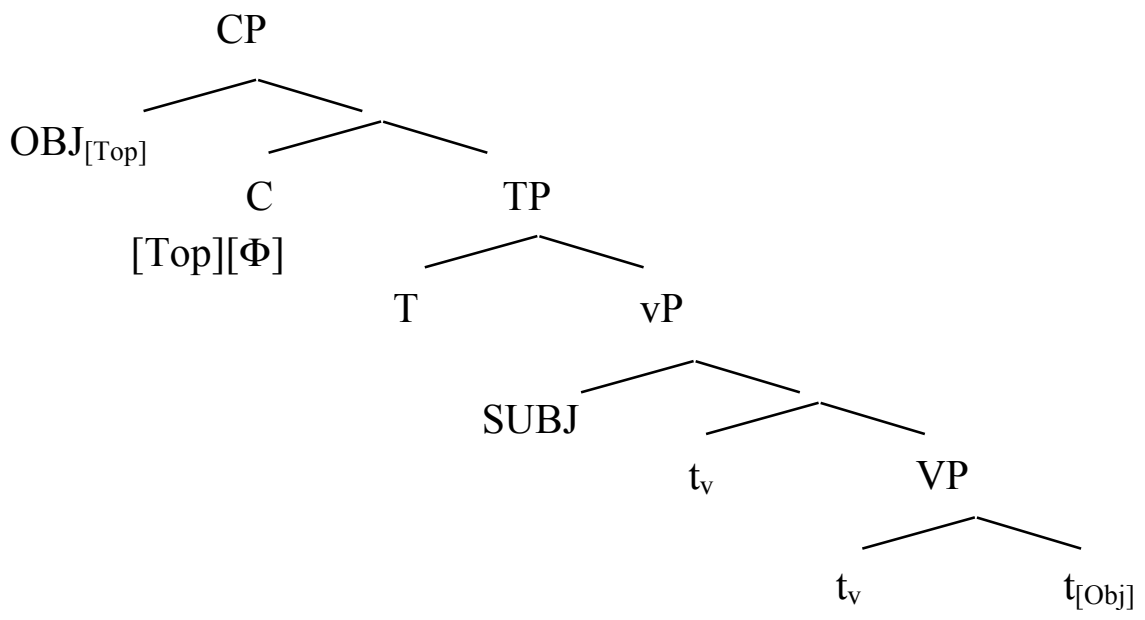

In contrast, Hamlaoui \& Makasso (2013) propose that the relevant Topic projection is located within IP and that Bantu languages vary with respect to agreement with a subject or an (IP-internal) topic. In most analyses, the logical subject remains in a VPinternal position (Kinyalolo 1991, Ura 2000, Carstens 2005, Henderson 2011) or raises to the Specifier position of a dedicated focus position (Ndayiragije 1999). This leaves problems with respect to locality (of the object moving across the subject) and case (as it is not clear how case is assigned to the subject). ${ }^{6}$ These problems are typically addressed by manipulating locality domains and the stage at which locality is computed

\footnotetext{
${ }^{6}$ There is also discussion within Minimalist approaches about whether all, some, or no Bantu languages have abstract case, and how argument licensing is achieved in Bantu (e.g. Carstens 2011, Diercks 2012).
} 
in the derivation, as well as by distinguishing 'Match' and 'Agree' relations, and their role in feature checking.

A slightly different approach is taken by Ndayiragije (1999), who argues that in patient inversion in Kirundi the postverbal logical subject undergoes movement to a low Focus position which accounts for its placement after the verb. A similar analysis is developed within LFG by Morimoto (2000, 2006), who argues that the NPs in patient inversion in Kinyarwanda and Kirundi should be analysed as topic and focus (and hence agreement as topic agreement), rather than as subject and object, reflecting a crosslinguistic difference between languages with patient inversion (and hence topic agreement) and those without (which therefore have subject agreement). However, we will see below that the cross-linguistic predictions of this proposal are not fully borne out. ${ }^{7}$ Furthermore, Whiteley \& Mganga (1969), Kimenyi (1980) and Gibson (2008), among others, show that the pragmatic effects of patient inversion in Kinyarwanda and Swahili are context-dependent and more subtle than can be captured by assigning topic and focus features alone.

Overall, the literature on patient inversion has tried to bring out the differences in relation to passives, and most analyses aim to distinguish the two constructions in terms of grammatical function changing (passives) vs. information structure-driven movement (patient inversion), the latter often involving movement of the object to a topic position. To the extent that the relationship between patient inversion and locative inversion is

\footnotetext{
${ }^{7}$ Even for Kinyarwanda and Kirundi, the evidence for a topic or a subject analysis is not straightforward (see Marten 2014: 142-143), and while Morimoto (2000) analyses the preverbal NP in Kirundi patient inversion as syntactic topic, Ndayiragije (1999) assumes that it is the grammatical subject.
} 
addressed, most analyses assume that locatives are subjects, following Bresnan \& Kanerva (1989), and preverbal patients are topics. However, as noted above, there is no direct correlation between the status of the preverbal NP (as subject or topic) and locative inversion. Furthermore, comparative evidence offered by many analyses - e.g. relating the presence of (some form of) patient inversion to the absence of grammatical subject agreement (Morimoto 2000, Hamlaoui \& Makasso 2013) - does not support a strict division between supposed 'locative inversion languages' and 'patient inversion languages', as we will show below.

\subsection{Semantic locative inversion and instrument inversion}

More recently, formal analyses have been proposed for semantic locative inversion and instrument inversion. In particular, Zeller's (2012a, 2013) Predication Phrase analysis provides a new way of looking at inversion constructions. In this analysis, the locative/instrument phrase does not start out in the verb phrase, but is the subject of a Predication Phrase (PrP, Bowers 1993), which takes a VP with the verb and the logical subject as complement. The diagram in (22) illustrates the derivation of the example in (21).

(21) Lezi zindlu zi-hlala aba-ntu aba-dala. (Zulu)

10.these 10.houses SM10-live 2-people 2-old

'Old people live in these houses.'

(Buell 2007: 108) 
(22) Inversion involving a Predication Phrase (Zeller 2013: 1123)

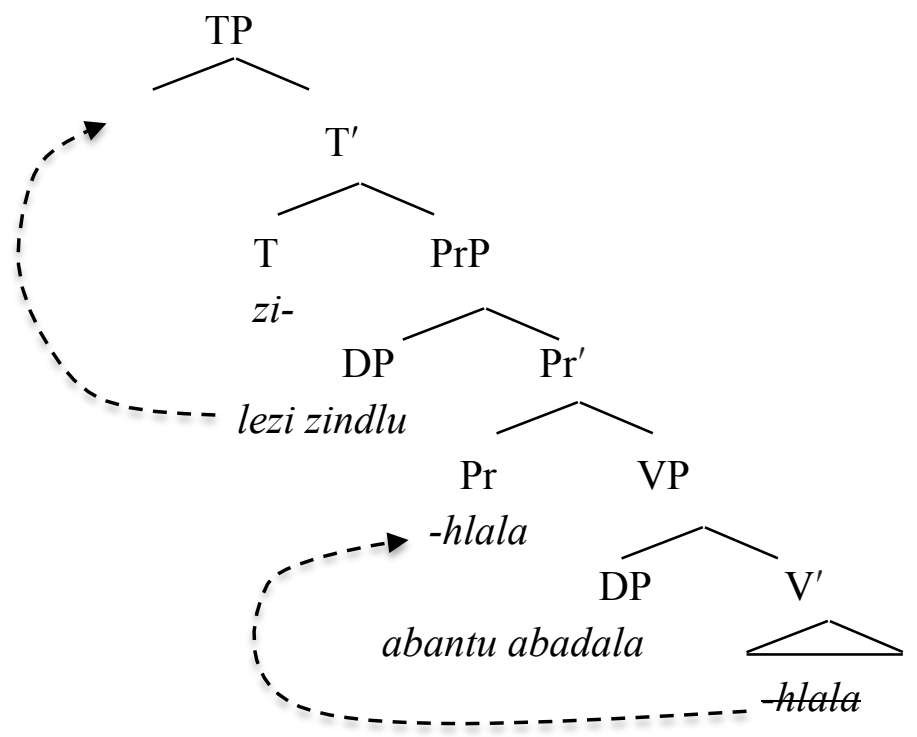

The main advantage of the analysis, which is based on Zulu, is that it explains the restriction of semantic locative and instrument inversion in Zulu to unaccusative verbs, and the absence of object marking.

With respect to the former, Zeller (2012a, 2013) notes a parallel between inversion and other instances of predication relations, such as copula constructions or adjectival predication, which all involve only a subject - in this analysis the subject of the PrP. However, inversion constructions - unlike other predication relations - are also found with verbs other than unaccusatives, in which case the proposal is that the obligatory applicative marker in these instances is a reflex of the predication head.

Zeller (2013: 1137-1138) notes that in addition to the restriction on object marking of the postverbal agent (as noted by Bresnan \& Kanerva (1989) in locative inversion) there is a more unexpected restriction on all object marking. Thus, it is not only object marking of the postverbal agent that is disallowed, but also object marking of the remaining theme argument - òmbàpírà 'letter' in example (23b): 
(23) (a) Pò-ndjúwó pé-tjáng-èr-à òvá-nàtjè ò-mbàpírà. (Otjiherero) 16-9.house SM16.HAB-write-APPL-FV 2-children 9-letter

'At the house write the children a letter.'

(Marten 2006: 115)
(b) *Pò-ndjúwó pé-ì-tjáng-èr-à
òvá-nàtjè
16-9.house SM16.HAB-OM9-write-APPL-FV 2-children
Intended: 'At the house write it the children'

(Zeller 2013: 1138)

The data show that the ban on object marking cannot be explained with reference to any quality of the postverbal agent (e.g. its deficient object qualities, or its focal status), but must be related to the construction as a whole. ${ }^{8}$ In the PrP analysis this is achieved by assuming that object marking requires a specific functional head located above the PrP, and so is inaccessible from positions within the VP (see Riedel 2009).

We agree with Zeller $(2012 \mathrm{a}, 2013)$ that the precise structural encoding of the information structural properties of inversion constructions, and whether the initial NP is projected in a 'subject' position or a 'topic' position, is related to context-dependent pragmatics. Although there may be language-specific constraints on the coding of subjects and topics, this is tangential to the analysis of inversion constructions. However, we believe that while the PrP analysis may be able to account for the specific

\footnotetext{
${ }^{8}$ This observation will play an important role in our own analysis, and we assume that the generalisation is correct. It is consistent with available descriptions of inversion constructions in the literature, although there is need for more detailed evidence from more languages.
} 
Zulu facts, it is too restrictive to be able to serve as a more comprehensive explanation for Bantu inversion constructions as a whole: We have already seen that inversion is not restricted to a specific predicate type, and there is no direct relation between inversion and applicative marking. ${ }^{9}$ Furthermore, in the $\operatorname{PrP}$ analysis, the preverbal NP is semantically not part of the verb phrase - it is the 'holder' (of the predication), that is, an entity of which a given state (introduced by the VP) holds as a property. While this is plausible for locations or even instruments, it is less easily applicable to patients in patient inversion. While we take a number of insights from Zeller's analysis, we will aim to develop a more comprehensive and generally applicable account in Section 5.

\subsection{Comparative evidence}

A final strand of research has addressed inversion constructions in a comparative context. We have already noted above that a number of formal analyses make reference to comparative evidence. For example, Morimoto (2000) proposes that there are three types of Bantu languages - those with topic agreement and patient inversion (Kinyarwanda), those with subject agreement and no patient inversion (Chichewa), and those with topic agreement but unexpectedly no patient inversion (Tswana). In addition to the conceptually problematic third category, the typology is empirically too restrictive as there is a fourth type of language, which has subject agreement and patient

\footnotetext{
${ }^{9}$ Zeller's (2012a, 2013) analysis of the applicative marker as head of the PredP also poses a challenge to a unified analysis of applicative constructions. It seems more likely - although conclusive comparative evidence is not yet available - that the applicative marker is related to the status of the inverted NP in the VP, which is more similar to what applicatives seem to do in other contexts.
} 
inversion (Swahili). Similar problems arise with Hamlaoui \& Makasso's (2013) proposal that Bantu languages have either (internal) topic agreement or subject agreement, which means, according to the authors, that languages with patient inversion should not have agreeing inversion (where the verb agrees with a following subject, for example in presentational constructions), yet this appears to be the situation in, for example, Kagulu (Petzell 2008), Luguru (Mkude 1974, Marten \& Ramadhani 2001) and Lusoga (Marten \& van der Wal 2014).

A more comprehensive typology of Bantu inversion constructions is provided in Marten \& van der Wal (2014), in which seven inversion construction types (formal locative inversion, semantic locative inversion, instrument inversion, patient inversion, complement inversion, agreeing inversion and default agreement inversion) and passives are compared across a subset of Bantu languages. Leaving aside agreeing inversion and default agreement inversion, which are not central to the current discussion, the results provide the relevant typological background for the analysis of Bantu inversion constructions developed in the present paper. In particular, the study proposes an overall unity of inversion constructions, which are defined by a set of nine variables as shown in Table 2. 


\begin{tabular}{|c|c|c|c|c|c|c|}
\hline 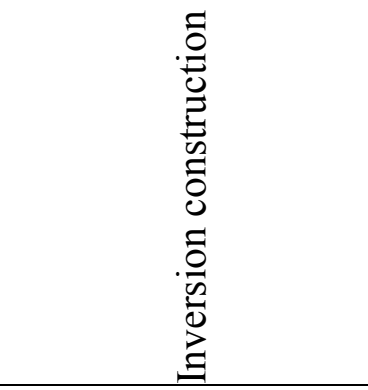 & 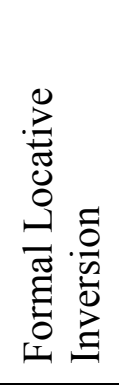 & 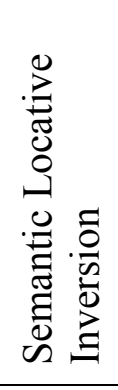 & 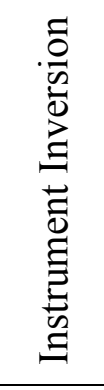 & 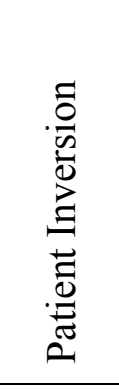 & 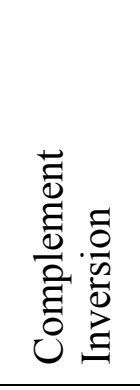 & $\begin{array}{l}\sum_{\infty}^{\infty} \\
0 \\
0 \\
0 \\
0\end{array}$ \\
\hline $\begin{array}{l}\text { V1 Verb-logical } \\
\text { subject order }\end{array}$ & $\checkmark$ & $\checkmark$ & $\checkmark$ & $\checkmark$ & $\checkmark$ & $\checkmark$ \\
\hline $\begin{array}{l}\text { V2 Postverbal/thetic } \\
\text { focus }\end{array}$ & $\checkmark$ & $\checkmark$ & $\checkmark$ & $\checkmark$ & $\checkmark$ & $\checkmark$ \\
\hline V3 No object marker & $\checkmark$ & $\checkmark$ & $\checkmark$ & $\checkmark$ & $\checkmark$ & $(\checkmark)$ \\
\hline $\begin{array}{l}\text { V4 Logical subject } \\
\text { cannot be omitted }\end{array}$ & $\checkmark$ & $\checkmark$ & $\checkmark$ & $\checkmark$ & $\checkmark$ & $x$ \\
\hline $\begin{array}{l}\text { V5 Close bond } \\
\text { between verb and } \\
\text { postverbal NP }\end{array}$ & $\checkmark$ & $\checkmark$ & $\checkmark$ & $\checkmark$ & $\checkmark$ & $x$ \\
\hline $\begin{array}{l}\text { V6 Overt preverbal } \\
\text { phrase/ referential } \\
\text { topic }\end{array}$ & $\checkmark$ & $\checkmark$ & $\checkmark$ & $\checkmark$ & $\checkmark$ & $x$ \\
\hline $\begin{array}{l}\text { V7 Thematic } \\
\text { restrictions on } \\
\text { preverbal element }\end{array}$ & $\begin{array}{c}\checkmark \\
\text { LOC }\end{array}$ & $\begin{array}{c}\checkmark \\
\mathrm{LOC}\end{array}$ & $\begin{array}{c}\checkmark \\
\text { INS }\end{array}$ & $\begin{array}{c}\checkmark \\
\text { PAT }\end{array}$ & $\begin{array}{c}\checkmark \\
\text { PROP }\end{array}$ & $x$ \\
\hline $\begin{array}{l}\text { V8 Morphological } \\
\text { marking of preverbal } \\
\text { phrase }\end{array}$ & $\checkmark$ & $x$ & $x$ & $x$ & $x$ & $x$ \\
\hline $\begin{array}{l}\text { V9 Agreement with } \\
\text { logical subject }\end{array}$ & $x$ & $x$ & $x$ & $x$ & $x$ & $x$ \\
\hline
\end{tabular}

Table 2

Variables for Bantu subject inversion constructions (based on Marten \& van der Wal 2014).

While clearly distinct from passives with respect to a number of variables, the five inversion constructions have the same values for all variables except V7 and V8. They differ only with respect to the thematic restriction on the preverbal NP and, in the case of locatives, with respect to the morphological marking of the preverbal NP (which is explicitly marked as locative in formal locative inversion). On the basis of this 
characterisation, the study investigates the distribution of inversion constructions in 46 Bantu languages. It shows that the majority of languages of the sample have formal locative inversion, while other inversion constructions are less common. Furthermore, the distribution of formal locative inversion and semantic locative inversion is almost complementary, with only a few languages having both. Marten \& van der Wal (2014) propose that the reason for this might be a change of locative marking in (mostly) southern Bantu languages (see also Marten 2010). This means that the apparent difference between formal and semantic locative inversion merely reflects the incidental difference in locative marking (see Buell 2007). Despite being based on a small sample, possible implicational relations can also be identified. Table 3 presents a relevant subset of data from Marten \& van der Wal (2014).

\begin{tabular}{|c|c|c|c|c|c|c|}
\hline & 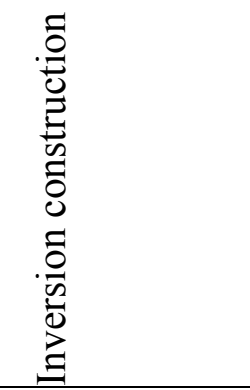 & 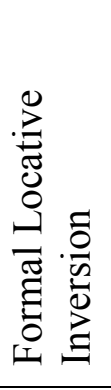 & 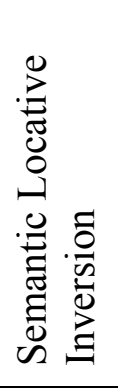 & 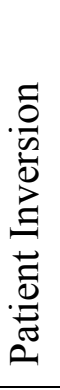 & 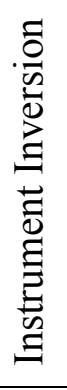 & 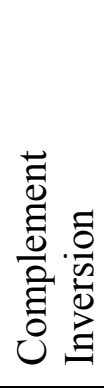 \\
\hline A43a & Basaa & 0 & 0 & 0 & 0 & 0 \\
\hline B865 & Nzadi & 1 & & 1 & 0 & \\
\hline B87 & Mbuun & 0 & 0 & 0 & 0 & 0 \\
\hline C322 & Dzamba & 1 & & 1 & & \\
\hline D25 & Kilega & $1 ?$ & & 1 & & \\
\hline E54 & Kîîtharaka & 0 & 1 & 0 & 0 & 0 \\
\hline G12 & Kagulu & 1 & & 1 & & \\
\hline G42 & Swahili & 1 & 1 & 1 & 0 & 0 \\
\hline JD42 & Kinande & 1 & & 1 & & \\
\hline JD61 & Kinyarwanda & 0 & $1 ?$ & 1 & & 1 \\
\hline JD62 & Kirundi & 0 & $1 ?$ & 1 & 1 & \\
\hline JE16 & Lusoga & 1 & & 1 & 1 & 0 \\
\hline JE32b & Olutsootso & 1 & 1 & & & \\
\hline
\end{tabular}




\begin{tabular}{lllllll}
\hline K332 & Dciriku & $1 ?$ & & 0 & & 0 \\
\hline M42 & Bemba & 1 & 0 & 0 & 0 & \\
\hline N13 & Matengo & 0 & 0 & 0 & 0 & \\
\hline N21 & Tumbuka & 1 & & 0 & $1 ?$ & \\
\hline N31 & Chichewa & 1 & 0 & 0 & & \\
\hline P13 & Kimatuumbi & 0 & 0 & 0 & 0 \\
\hline P22 & Yao & 1 & & 1 & & \\
\hline P31 & Makhuwa & 0 & 0 & 0 & 0 & \\
\hline R31 & Otjiherero & 1 & 0 & 0 & & \\
\hline S31 & Tswana & 0 & & 0 & 0 & \\
\hline S32 & Sesotho & 0 & 0 & 0 & 0 \\
\hline S33 & N. Sotho & 0 & 0 & 0 & 0 & \\
\hline S42 & Zulu & 0 & 1 & 0 & 1 & 1 \\
\hline S43 & Swati & 0 & 1 & & 1 & 0 \\
\hline S44 & Ndebele & 0 & 1 & 0 & 1 \\
\hline $1=$ construction attested, $0=$ construction absent, blank $=$ value not known, \\
$?=$ construction appears to be present, but this is not fully clear from the sources
\end{tabular}

Table 3

Distribution of inversion constructions in languages with at least two values for inversion constructions (based on Marten \& van der Wal 2014).

The data in Table 3 show that all languages which have instrument inversion, and all languages which have patient inversion, also have (formal or semantic) locative inversion. This means that rather than being in complementary distribution, the presence of instrument or patient inversion implies the presence of locative inversion (though not vice versa). However, no clear implication appears with respect to patient and instrument inversion - Nzadi having the former but not the latter, and Ndebele showing the inverse pattern.

In light of the analysis of inversion constructions and the distributional results identified, Marten \& van der Wal (2014) consider thematic hierarchies central to the explanation of cross-linguistic variation in Bantu inversion constructions. This is a notion which we expand upon in the analysis presented in Section 5. 


\subsection{Summary}

We have shown that the literature on Bantu inversion provides a number of formal analyses for different construction types. Three main aspects of inversion constructions stand out from previous research. First, all inversion constructions share a set of core structural and interpretational qualities: a preverbal NP expressing a thematic role other than the logical subject; a postverbal NP which expresses the logical subject and is obligatory; no object marking; the preverbal NP is typically more topical and the postverbal NP more focal, although the construction may also give rise to thetic readings; and a close 'bond' between verb and postverbal NP. Secondly, variation between different inversion constructions and their cross-linguistic distribution is related to thematic restrictions on the predicates and/or arguments which can take part in inversion constructions - in Bemba, for example, locatives invert, but instruments do not. Finally, cross-Bantu variation in inversion constructions is independent of the difference between subject and topic.

In the following sections we develop a unified account of Bantu inversion constructions addressing the constructions' common core characteristics from the perspective of Dynamic Syntax. We employ the concepts of underspecification and update which are central to DS, and distinguish processes of structure building from the pragmatic functions for which these structures can be put to use. Before we present the details of our analysis, the following section provides an introduction to the framework.

\section{DYNAMIC SYNTAX}

Dynamic Syntax is a formal model of utterance description which aims to reflect the cognitive architecture that enables hearers to construct semantic representations of 
content through combining lexical and contextual information (Kempson et al. 2001, Cann et al. 2005, Kempson, Gregoromichelaki \& Howes 2011). Syntax is seen as a parsing device, contributing to the process from lexical access to the establishment of some interpretation in context, and no other (static) knowledge of syntax is assumed to be required for syntactic explanation. The process of structure building is goal-driven and incremental, and a single level of mental semantic representation is assumed. This is modelled as 'tree growth', developing partial semantic trees, formalised in the Logic of Finite Trees (Blackburn \& Meyer-Viol 1994). The establishment of an interpretation involves the interaction of structural, syntactic, and lexical processes, with pragmatic inference also playing a central role in the establishment of (partial) representations. Throughout the process, more information is accumulated, underspecified terms enriched, and requirements are resolved.

A simplified derivation of a transitive clause such as John likes Sally is presented in (24) below, which shows the dynamics of the mapping from linearly-ordered words to structured semantic representations. Tree growth takes place from a minimal starting tree of only one node, in (24a), to a fully-fledged (although here simplified) semantic representation in (24f). At the end of the structure building process, every node in the fully developed tree is annotated with content information and type information $(\mathrm{Ty}=$ type, Ty(t) = 'truth'/proposition, Ty(e) = 'entity'/term, Ty(e $\rightarrow$ t $)=$ predicate, Fo = formula, $\diamond=$ 'pointer' indicating the current node under development, ? = requirement). 
(24) Derivation of John likes Sally

(a) $\quad$ Ty $(\mathrm{t}), \diamond$

(c)

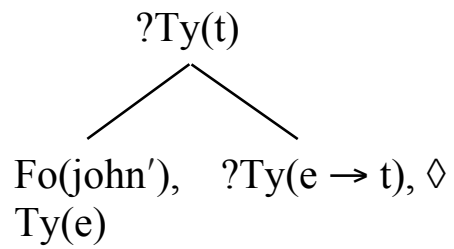

(e)

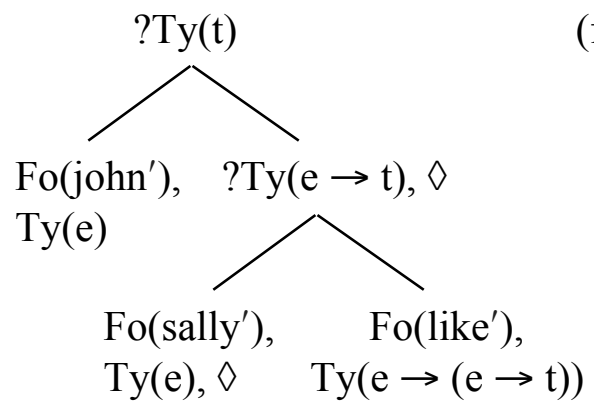

(b)

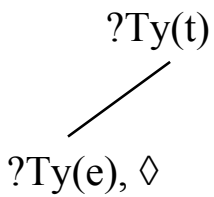

(d)

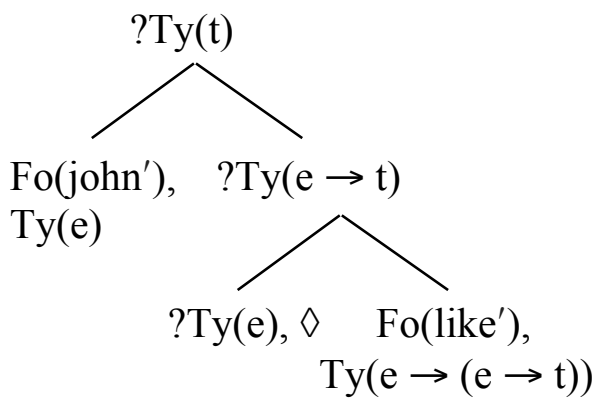

(f) $\quad \operatorname{Ty}(\mathrm{t}), \operatorname{Fo}\left(\right.$ like' $^{\prime}\left(\right.$ sally'$\left.^{\prime}\right)\left(\right.$ john $\left.\left.^{\prime}\right)\right), \diamond$
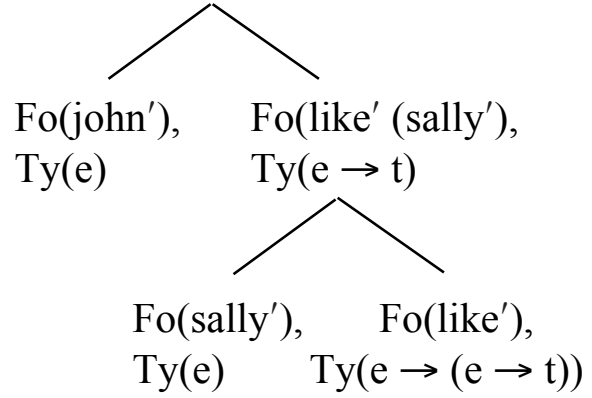

The parsing process starts with a requirement for a Ty(t) expression, reflecting hearers' expectation to derive a propositional object which will interact with their cognitive environment (following Relevance Theory, Sperber \& Wilson 1995). The query (?) indicates that this is a requirement to be fulfilled in the course of the parse (no outstanding requirements are allowed in the final tree state), and the pointer symbol ' $\diamond$ ' indicates the current node under development. Structure building rules and the lexical information from John result in the steps in (24b) and (24c), and lexical information from like (ignoring tense and agreement for the moment) results in (24d), where subcategorised information licenses building of both the predicate node and the 
requirement for an object (lexical information will be shown in more detail below). The object Sally is parsed, resulting in the tree shown in (24e) and the object node is duly annotated. All the information accumulated during the parse is combined up the tree, thus fulfilling the original requirement for a Ty(t) expression. This simplified example shows how, through parsing lexical input, tree structure develops and requirements are eliminated. Note that DS trees are semantic representations, and do not represent word order or other syntactic aspects of the sentence. Word order is expressed in the system by the growth of semantic representation from words encountered, and so both the process and the result of the derivation are part of syntactic explanation.

Tree nodes are defined through their relation to each other, which is expressed by tree modalities (e.g. $<\downarrow_{0}>=$ argument daughter, $\left\langle\downarrow_{1}>=\right.$ functor daughter, $\langle\uparrow>=$ mother, etc.). These can also be used for expressing pointer movement within the tree. A central part of the DS system is the concept of underspecification and different underspecified tree relations can also be defined (e.g. $\left\langle\downarrow^{*}>=\right.$ an unspecified number of daughter relations):

(25) Dynamic Syntax tree relations

(a) Fixed node

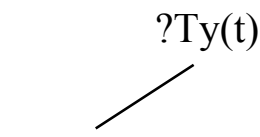

$<\uparrow_{0}>$ ? Ty(t) (b) Unfixed node

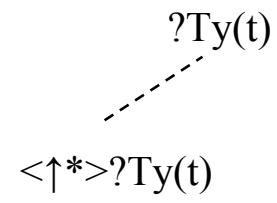

(d) Linked node

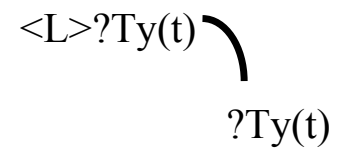


In addition to fixed tree relations, as in (25a) below, tree nodes may be unfixed with respect to the root node, as in (25b), or unfixed with respect to the local functor node, as in $(25 \mathrm{c})$, providing two different notions of locality within the tree. A Link relation is also defined, in (25d), connecting two otherwise independent trees by setting up a term which is shared by the two trees and typically serves as the context against which the ensuing tree is evaluated.

Unfixed nodes and locally unfixed nodes can be introduced by the corresponding rules of *Adjunction ('star adjunction') and Local *Adjunction or through lexical actions, and Link relations can be launched as a result of the Link Adjunction rule. It is important to note that given that tree nodes are defined with respect to each other, only one unfixed node of each kind can be maintained at any one time since two unfixed nodes of the same modality are identical in terms of tree logic and will therefore collapse onto each other. This places a considerable structural restriction on the system, which we will exploit below (see Kempson, Cann \& Marten 2013). Information can be introduced early (i.e. at the left periphery) via any of the mechanisms, or late (at the right periphery) on an unfixed node or a Link structure. The options in (25) above are defined as being available at the outset and at the end of the derivation. However, the interpretational effects will be different as the two contexts differ - i.e. before anything is parsed and after almost all information has been assembled.

In order to use the DS system for our analysis of Bantu inversion constructions, we will next set out our assumptions about Bantu clause structure and how this can be analysed in DS (see Cann et al. 2005; Marten 2007, 2011; Marten, Kempson \& Bouzouita 2008; Gibson 2012). 
We assume that individual morphemes in Bantu verbs have their own lexical specifications and make independent semantic and syntactic contributions (see Julien 2000). ${ }^{10}$ Morphemes are parsed from left to right, and their contribution must be analysed in the context of information available from the preceding lexical input. We will take an example from Swahili, in (26) below, to illustrate this. Bantu languages exhibit widespread subject (and object) pro-drop and it is possible for a Swahili clause to consist of only an inflected verb - normally in a context in which the referent of the subject marker can be identified from the context:
(26) Wa-ta-fik-a.
(Swahili)
SM2-FUT-arrive-FV
'They will arrive.'

We assume that subject markers are pronominal clitics (see Bresnan \& Mchombo 1987), and that they annotate locally unfixed nodes (Marten 2011, Gibson \& Marten 2015). Thus, a lexical entry for the class 2 subject marker wa- (which represents animate plural entities) looks like (27): ${ }^{11}$

\footnotetext{
${ }^{10}$ We do not address the DS analysis of phonological representations, but see Bouzouita (2009) for a detailed analysis of (diachronic) lexicalisation processes in the Spanish clitic system, and Marten (2002: 10-21) for a more general discussion of the role of phonology in DS.

${ }^{11}$ The ellipsis (...) in the THEN statement in (27) indicates that the lexical entry may be more complex to account for actions induced in other parsing contexts. Here we represent only relevant information in the context of an example such as (26).
} 


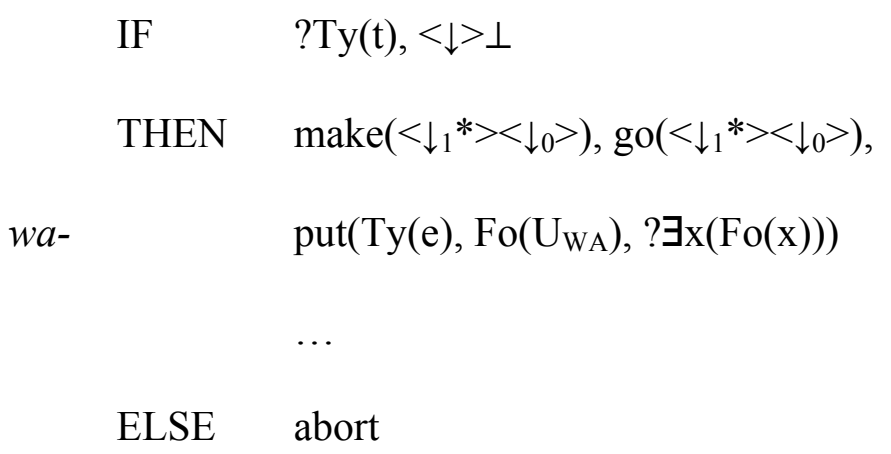

Lexical entries in DS have standardly three types of statements (although more complex lexical entries can result from nesting of these statements): An IF statement specifying the conditions holding at the current node when the lexical entry is parsed, a THEN statement which contains the lexical actions (such as 'make', 'go' and 'put') to be performed if the conditions of the IF statement are met, and an ELSE statement for actions performed when the conditions of the IF statement are not met. In (27) the conditions are that the current node is the root node with the requirement ?Ty(t), and that at this stage, there are no fixed nodes below the root node (formally, that at any fixed daughter node falsum $(\perp)$ holds). This ensures that the subject marker is parsed at the outset of the derivation and crucially, before the introduction of any other fixed structure. Any preverbal NPs are consequently projected onto an unfixed node or a Link structure, further discussed below.

If the conditions of the lexical entry in (27) are satisfied, the lexical actions of the THEN statement license the building of a locally unfixed node from the root node ('make $\left(<\downarrow_{1} *><\downarrow_{0}>\right)$ '), the movement of the pointer to this node $\left({ }^{\prime} \operatorname{go}\left(<\downarrow_{1} *><\downarrow_{0}>\right)\right.$ '), and its decoration (or annotation) with the type value $\mathrm{Ty}(\mathrm{e})$ and with the underspecified formula value $\mathrm{Fo}\left(\mathrm{U}_{\mathrm{WA}}\right)\left({ }^{(} \operatorname{put}\left(\mathrm{Ty}(\mathrm{e}), \mathrm{Fo}\left(\mathrm{U}_{\mathrm{WA}}\right), ? \exists \mathrm{x}(\mathrm{Fo}(\mathrm{x}))\right)\right.$ '). $\mathrm{U}$ is a metavariable over 
formula expressions and WA a restriction on the substitution of this variable to expressions compatible with WA-semantics (i.e. class 2 nouns which represent animate plurals). Finally, a requirement for a full formula value to replace the metavariable is introduced $(? \exists \mathrm{x}(\mathrm{Fo}(\mathrm{x})))$. We assume that $(27)$ is parsed in a context where watalii 'tourists' can be identified from the context as an appropriate concept for the underspecified value for the subject marker, and so the formula value is updated to Fo(watalii'), reflecting contextual (not lexical) update, as illustrated in (28); note that pragmatic information may contribute to tree development just like lexical information:

(28) Wa- ...

SM2-

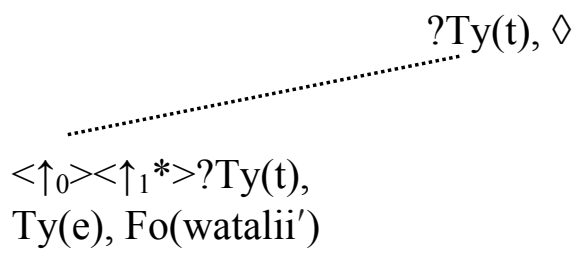

The next element to be parsed is the future tense marker $t a-$. The lexical actions for $t a-$, shown in the lexical entry in (29), contribute temporal information (which we express as a simplified feature 'Tns(Fut)' on the root node) and build fixed nodes for the (logical) subject and the predicate (reflecting the historical origin of many Bantu tense markers, including Swahili ta-, as verbs, see Gibson 2012). 


$$
\begin{array}{ll}
\text { IF } & \text { TTy(t), }<\downarrow_{1} *><\downarrow_{0}>\operatorname{Ty}(\mathrm{e}),<\downarrow_{0}>\perp \\
\text { THEN } & \operatorname{put}(\operatorname{Tns}(\text { Fut })), \\
& \operatorname{make}\left(<\downarrow_{0}>\right), \operatorname{go}\left(<\downarrow_{0}>\right), \operatorname{put}(? \operatorname{Ty}(\mathrm{e} \rightarrow \mathrm{t})), \operatorname{go}(<\uparrow>), \\
& \operatorname{go}\left(<\downarrow_{0}>\right), \operatorname{put}(? \operatorname{Ty}(\mathrm{e}))
\end{array}
$$$$
\text { ta- }
$$

ELSE abort

The requirements of the IF statement are that the pointer be at the root node with a ?Ty $(t)$ requirement, that there exists a locally unfixed node of Ty(e), and that there is no

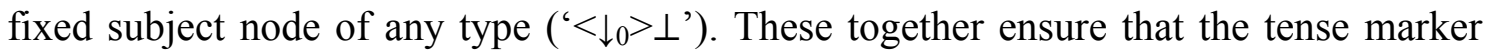
follows the subject marker, and cannot be parsed, for example, as the first element of the verb. The lexical actions then add the tense annotation and build a functor and an argument node, both annotated with requirements:

(30) Wa-ta- ...

SM2-FUT-

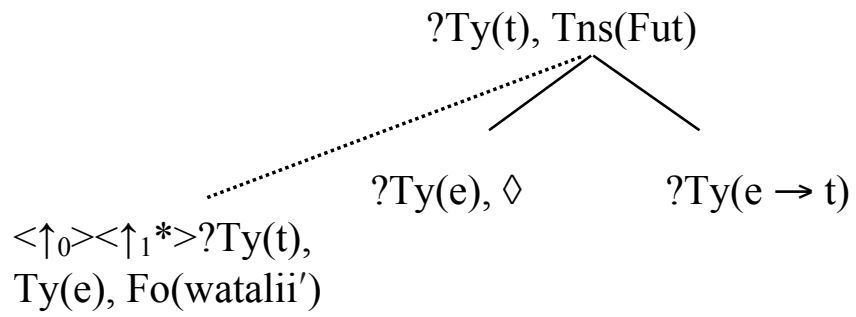

At this stage, the locally unfixed node can (and here does) merge with the fixed subject node since the unfixed node is of Ty(e) and the fixed subject node has a requirement for a node of this type (?Ty(e)). The fixed tree position provides a proper update to the underspecified tree position of the locally unfixed node, satisfying the erstwhile outstanding requirements: 
(31) Wa-ta- ...

SM2-FUT-

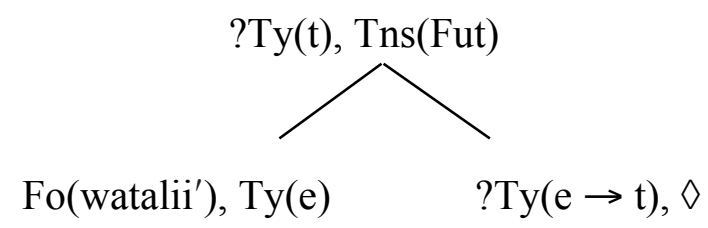

With this step, Fo(watalii') is established as decorating the logical subject node. ${ }^{12}$

Finally, the predicate node is annotated with lexical information from the verb -fik'arrive':

$$
\begin{array}{lll} 
& \text { IF } & \text { ?Ty }(\mathrm{e} \rightarrow \mathrm{t}) \\
-f i k- & \text { THEN } & \operatorname{put}\left(\mathrm{Fo}\left(\mathrm{fik}^{\prime}\right), \operatorname{Ty}(\mathrm{e} \rightarrow \mathrm{t})\right) \\
& \text { ELSE } & \text { abort }
\end{array}
$$

The final steps of the derivation result in the projection of the accumulated information up the tree through steps of function-application over the type annotations.

\footnotetext{
${ }^{12}$ Merging of nodes is optional, and the locally unfixed node does not need to merge at the subject node. A delayed process of merge may result in the initial information ending up as decorating an object node, which is what we assume underlies inversion constructions.
} 
(33) Wa-ta-fik-a.

'They will arrive.'

SM2-FUT-arrive-FV

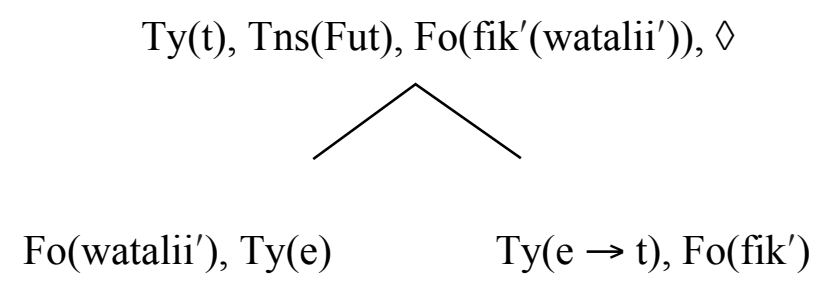

At this stage all morphemes have been parsed, any underspecification has been resolved, and all requirements are fulfilled. The derivation is complete and the tree wellformed and fully annotated. The result is a semantic representation of the proposition that the tourists will arrive.

In the course of the parsing process, a locally unfixed node has been built with underspecified structural and semantic information. However, since this underspecification has been resolved by enriching the metavariable from contextual information, and the node has been merged at the subject node, there is no indication of this in the final structure. In fact, the final structure would be the same for a corresponding sentence with an overt lexical subject NP: In DS, steps taken in the establishment of structure are as important as the final tree, and identical final trees for different surface strings may only be distinguishable by the parsing mechanisms (i.e. the intermediate steps) employed in their derivation and their interaction with contextual information.

With the theoretical and formal background in place, we can now address the modelling of Bantu inversion constructions in DS. We will start by looking at shared structural and interpretational qualities before turning to variation in distribution. 


\section{A DS PERSPECTIVE ON BANTU INVERSION CONSTRUCTIONS}

In this section we develop a formal analysis of inversion constructions within DS, and show how this addresses the core properties of the construction in terms of structure and interpretation. We then turn to the question of cross-linguistic variation.

\subsection{Structure building}

At the centre of our analysis is a formal account of structure building which, we assume, characterises all Bantu inversion constructions. The three central aspects of the account are:

- Information from the preverbal NP can be projected onto a Link structure at the outset of the parse - setting up a term in the context and thus fulfilling a more topic-like function. Alternatively, it can be projected unto an unfixed node which merges with the locally unfixed node, in a more subject-like structure. However, while there might be language-specific restrictions on one or the other strategy, there are no construction-specific restrictions.

- The locally unfixed node projected by the 'subject' marker which agrees with the preverbal NP merges not at the (logical) subject node, but at the object node. Since there can be only one locally unfixed node at a time, and since the locally unfixed node is only fixed after the verb has been parsed (and has introduced a fixed object node), no further locally unfixed nodes can be built to host an object marker - hence debarring object marking.

- Pragmatic focus effects are related to the context and arise through the late placement of the logical subject. There is a stage in the derivation where an 
incomplete proposition has been established, and the last remaining value is supplied by the postverbal logical subject, giving rise to pragmatic effects, and allowing the hearer to derive additional, contextual meaning over and above the proposition expressed.

The following snapshots of the parse of example (34) (repeated from (12) above) illustrate the analysis in more detail.

(34) M-lima u-me-pand-a wa-tu. (Swahili)

3-hill SM3-PRF-climb-FV 2-person

'People have climbed the hill.' (lit.: 'The hill has climbed the people.')

(Whiteley \& Mganga 1969: 115)

At the outset of the parse, the only two options for the projection of information from the initial NP are as a Link structure or as unfixed node. Other potential parsing strategies are unavailable as no fixed node is yet available, and we assume that locally unfixed nodes are built lexically (through pronominal clitics) in Bantu, as seen above. Link structures allow the setting up of a term as context against which the following information is interpreted - corresponding to a pragmatic topic. Formally, the linked structure constitutes an individual partial tree which is linked to the ensuing main tree by a shared term, expressed through a requirement on the main tree to contain a copy of the formula value of the linked tree. In (35) below, this is the requirement at the root node that Fo(mlima') be part of the eventual tree to be developed, although the exact location is not yet known. This requirement can later be fulfilled by a pronominal 
element in the main tree, such as that supplied by subject or object markers, which can be interpreted as Fo(mlima').

(35) M-lima ...

3-hill

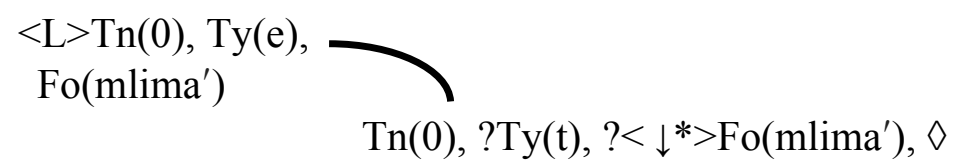

An alternative way of introducing the information from the initial NP is by building an unfixed node (by *Adjunction) with the requirement ?Ty(e), which can be annotated by information from mlima 'hill'. For the remainder of the paper, we model initial NPs using unfixed nodes, but the Link structure option at the outset of the parse is always present. There are differences between the two strategies, further discussed below, in terms of restrictions on further tree growth and information structure (see Marten 2011) and with respect to cross-linguistic variation in the coding of initial NPs (e.g. Gibson 2012), but for the present illustration the differences are not crucial. The building of an unfixed node for the initial NP is shown in (36):

(36) M-lima ...

3-hill

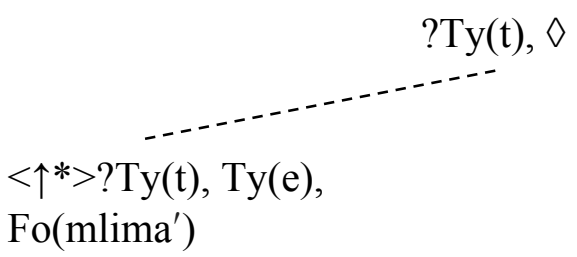

As in the sample derivation in Section 4 above, the morpheme $u$ - annotates a locally unfixed node, which, being a different kind of unfixed node (a more restricted one 
which can only be interpreted within the local domain), can co-occur with an unfixed node.

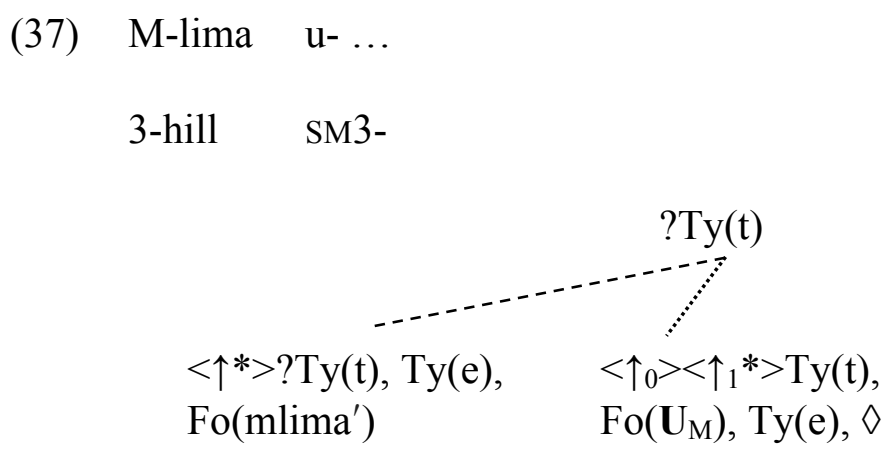

The two nodes can merge since they are both Ty(e) nodes, the formula value Fo(mlima') provides an appropriate update of the metavariable $U_{M}$ (compatible with 'm-class' nouns) and the more specific modality $<\uparrow_{0}><\uparrow_{1} *>\mathrm{Ty}(\mathrm{t})$ provides a proper update of the less restricted $<\uparrow^{*}>\mathrm{Ty}(\mathrm{t})$. This results in a locally unfixed node annotated with Fo(mlima'). The tense marker then introduces temporal information, ${ }^{13}$ and two fixed nodes with requirements for a subject and a predicate.

(38) M-lima u-me-...

3-hill SM3-PRF-

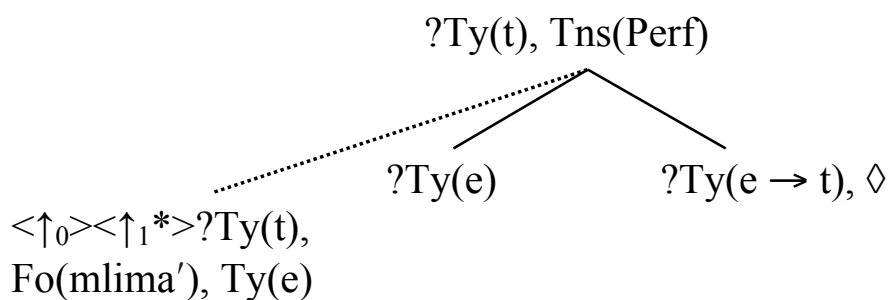

\footnotetext{
${ }^{13}$ This is a pro tem representation of temporal and aspectual information and does not constitute a formal analysis, but will suffice for the present purpose.
} 
At this stage, the locally unfixed node could merge with the fixed subject node - as in the sample derivation above - but nothing forces this move, and in the present derivation, the locally unfixed node does not merge, thus being able to later annotate the object node. ${ }^{14}$ This also means that no further locally unfixed node can be built at this stage which would be needed to host an object clitic, and hence that object marking is not possible: The choice of NOT merging the initial locally unfixed node at the subject node leads to the unavailability of a further locally unfixed node to host an object marker.

The pointer remains at the predicate node, and information from the transitive verb -pand- 'climb' can be parsed. As (39) shows, this builds and annotates a new predicate node, and builds an object node with a requirement for an expression of Ty(e). The final vowel $-a$ then moves the pointer to the object node.

(39) M-lima u-me-pand- ...

3-hill SM3-PRF-climb-

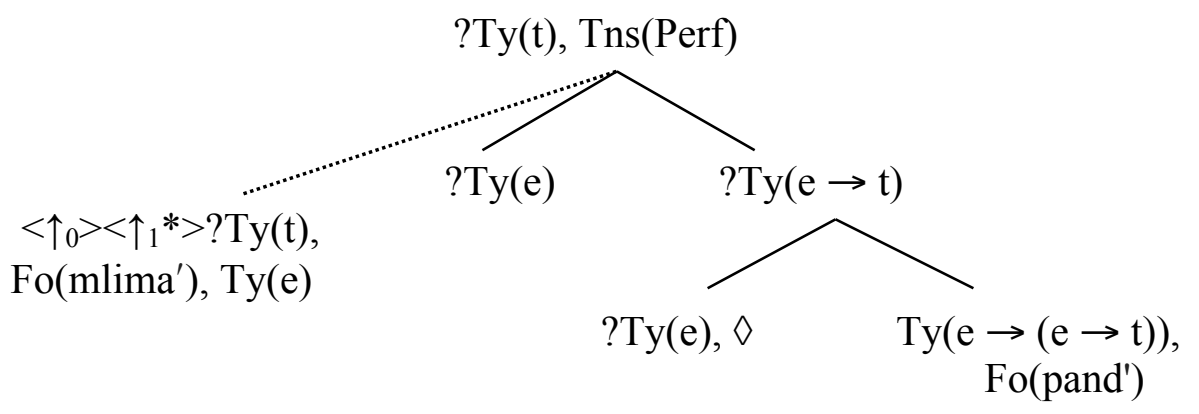

${ }^{14}$ An important feature of DS is the availability of multiple parsing processes at any one time. At early stages in a derivation there might be parallel parses and multiple strategies available for parsing the same string. Typically, however, these options are reduced as more information is provided and the parse progresses. 
Structurally, the locally unfixed node could merge with the fixed subject node, but this would result in the semantically implausible interpretation of a 'fairy tale' reading in which hills are agents. This is therefore not a likely option, and the locally unfixed node is merged at the object position, as seen in (40). Because of this, the requirement on the subject node for a Ty(e) expression remains outstanding.

(40) M-lima u-me-pand-a ...

3-hill SM3-PRF-climb-FV

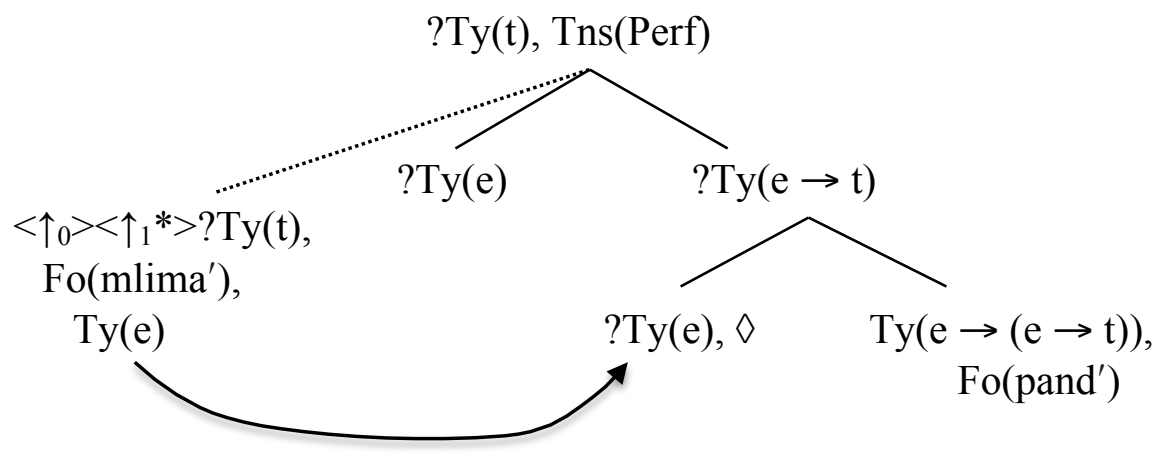

The only possibility to complete the derivation (since no requirements are allowed to remain once the parse is complete) is to provide lexical input for the annotation of the subject. The pointer thus returns to the subject node (through combining semantic information up the tree and by anticipation of information holding at the subject node), expecting further lexical input. This is provided by the postverbal NP and the node is duly annotated: 


\section{(41) M-lima u-me-pand-a wa-tu ... \\ 3-hill SM3-PRF-climb-FV 2-person}

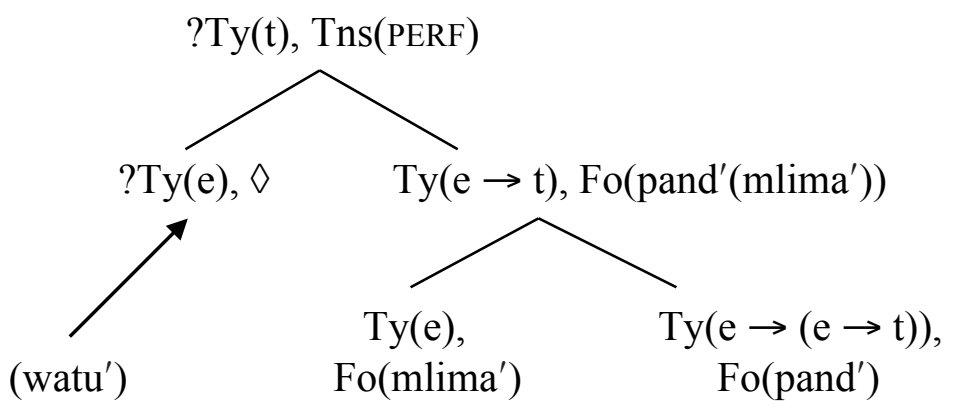

The postverbal NP expressing the logical subject cannot be omitted since at the time the verb has been parsed, there is no subject information. Since the logical subject position is not annotated by the initial unfixed node (which is associated with the object position), an overt subject NP is necessary. The close (morphological or prosodic) association with the verb marks the obligatory continuation of the parse.

Having set out the basic syntactic analysis of inversion constructions with reference to patient inversion, in the following sections we will address specific aspects of the analysis: its applicability to other inversion constructions, especially formal locative inversion; the explanation of pragmatic and information structure effects in our analysis; and the role of thematic restrictions in explaining cross-linguistic variation.

\subsection{Extension to other inversion types}

Our sample derivation in the previous section was based on an example of patient inversion. However, our claim is that all inversion constructions discussed here share the same steps of structure building. There are two main issues related to this: The locative marking in formal locative inversion and the status of locatives, instruments, 
and complements as arguments of the predicate - or at least as semantically being part of the predicate. The latter point is important since the eventual position of the initial expression as being fixed only after the verb has been parsed lies at the heart of our analysis of the previous section. Strictly speaking, what our account assumes is that the initial expression does not annotate the logical subject node, but some node which is only introduced once the verb is parsed. This node was the object node in example (40) above, but for other inversion types, this might also be a VP-adverb node, that is, a node which takes a Ty $(\mathrm{e} \rightarrow \mathrm{t})$ expression as input and returns a Ty $(\mathrm{e} \rightarrow(\mathrm{e} \rightarrow \mathrm{t}))$ expression, licensing the introduction of a Ty(e) modifier. Since this node would be only available once the verb has been parsed, the essence of our analysis still stands. However, there are some indications that the initial expression in all inversion constructions ends up in an argument position, and this is the assumption we adopt here.

With respect to the difference between formal locative inversion and patient inversion, it is sometimes assumed that the formal marking makes the locative more like a prepositional phrase than a noun phrase, and that this, and the locative semantics, indicate the status of the locative as an adjunct (not as an argument, as the patient in patient inversion). The two constructions would thus be underlyingly different. However, cross-linguistic evidence does not support this view. As noted above, formal and semantic locative inversion are in near complementary distribution, and overall semantic locative inversion is found in languages in which locatives have been reanalysed from nouns as prepositional phrases (Buell 2007, Marten 2010, Marten \& van der Wal 2014). This means that in both cases the relevant inverted phrases are nominal, not prepositional. 
Furthermore, evidence from object marking suggests that locatives can often be object marked like other objects, indicating their object-like status (see e.g. Riedel \& Marten 2012):
(42) Ni-ha-many-a
Mlogholo. (Luguru)
SM1 ${ }^{\text {st }}$ SG-OM16-know-FV Morogoro
'I know Morogoro (i.e. the place).'

(Marten \& Ramadhani 2001: 263)

Further corroborative facts come from so-called 'disjoint agreement' locative inversion in Lubukusu (Diercks 2011):
(43) Mú-mú-siirú kw-á-kwá-mó kú-mú-saala. (Lubukusu)
18-3-forest SM3-PST-fall-PROCL18 3-3-tree
'In the forest fell a tree.'

(Diercks 2011: 703)

In these constructions, the locative phrase is fronted, but verbal subject marking agrees with the postverbal agent. In addition, a postverbal clitic agreeing with the locative is obligatory. The clitic can be seen as providing a decoration of the logical object node, and so the construction is in this respect identical to more canonical locative inversion 
cases, where, in our analysis, information from the locative phrase also annotates the semantic object node. ${ }^{15}$

Although we do not develop this further here, it is worth noting that the concept of verbal type underspecification developed in Marten (2002) provides a formal means to express this idea in DS, since it allows the introduction of (semantically optional) locative (and other) expressions as part of the verb phrase through the use of underspecified subcategorisation information which is enriched in specific occurrences of the relevant predicate.

Another source of evidence comes from the interaction of inversion and applicative marking. Although more empirical work is needed, it has often been noted that applicative marking plays a role in some inversion constructions (e.g. Marten 2006, Buell 2007, Zeller 2013). For semantic locative inversion in Zulu, Zeller (2013: 1111) notes that inversion with verbs other than unaccusatives has to be licensed by an applicative marker.

(44) (a) La ma-doda a-sebenz-a ku-lesi si-tolo. (Zulu) DEM6 6-man SM6-work-FV LOC-DEM7 7-store 'These men work at this store.'

${ }^{15}$ Lubukusu also has so-called 'repeated agreement locative inversion', where both the subject marker and the postverbal clitic agree with initial locative phrase. More DS work on Lubukusu clause structure (e.g. on subject and object marking, postverbal clitics, topic structures, or resumption) would be needed to develop an analysis of this construction type. 
(b) Lesi si-tolo si-sebenz-el-a la ma-doda.

DEM7 7-store SM7-work-APPL-FV DEM6 6-man

'These men work at this store.'

(Zeller 2013: 1111)

Zeller (2013) proposes that applicative marking such as in (44b) is an overt reflex of a PrP head. However, in view of other functions of applicatives, a more parsimonious analysis, following Buell (2007), would be to assume that the applicative licenses the construal of the locative as an argument of the verb.

There is not much work on complement inversion, and we only have limited data, such as examples like (45) below (repeated from (5) above).

(45) Gu-kina gu-kuund-a aba-ana. (Kinyarwanda) 15-play SM15-like-FV 2-children

'It is the children who like to play.' (lit.: 'Playing likes the children')

(Morimoto 2000: 183)

Complement inversion can be subsumed under the present analysis with empirical support from object marking, analogous to the object marking evidence for locatives. As (46) shows, class 15 infinitives can function as objects and can be object marked (see Visser 1989): 
$\begin{array}{lll}\text { (46) A-li-ku-siki-a } & \text { ku-imba } & \text { kw-etu. (Swahili) } \\ \text { SM1-PST-OM15-hear-FV } & \text { 15-sing } & \text { 15-our }\end{array}$

'S/he heard (it) our singing.'
(Marten, field notes)

We thus assume that in all inversion constructions discussed here, the locally unfixed node annotated with information from the preverbal phrase will merge at a verbal object position, in line with the overall analysis developed above. This is supported by the morphosyntactic and interpretational similarities shared by all constructions, and by the cross-linguistic distribution of inversion constructions across Bantu, which indicates that these are essentially the same construction, differing only in the thematic nature of the inverted phrase. Before we address this source of variation, we discuss aspects of the information structure of inversion constructions.

\subsection{Topic, focus, and information structure}

The second outstanding question related to our analysis is the question of information structure. As discussed in Section 2, inversion constructions are associated with specific pragmatic and information structure effects, with the preverbal phrase typically more topical, and the postverbal phrase more focal. Alternatively, the whole construction may give rise to a thetic reading. Presentational focus is illustrated in (47), exclusive focus with the postverbal phrase modified by kuphela 'only' is shown in (48), new information focus in (49), contrastive focus in (50), and a thetic statement indicating surprise in (51): 
(47) Fá-se-tlharé-ng gó-émé ba-símané.

(Tswana)

16-7-tree-LOC SM17-stand.PRF 2-boys

'By the tree stand the boys.'

(Demuth \& Mmusi 1997:8)

(48) Lezi zin-dlu zi-hlal-a aba-ntu aba-dala kuphela. (Zulu) DEM10 10-house SM10-stay-FV 2-person 2-old only

'Only old people live in these houses.'

(Zeller 2013: 1116)

(49) Ici-ya ci-tul-a imw-ana.

(Luguru)

7-pot SM7-break-FV 1-child

'The child broke the pot.' (In answer to: 'The pot, who broke it?')

(Mkude 1974: 133)

(50) Ivyo bi-tabo bi-á-somye Yohani.

(Kirundi)

those 8-book SM8-PST-read.PFV Yohani

'Yohani (not Peter) read those books.'

(Ndayiragije 1999: 424)

(51) Ki-wanja ki-na-tu-a ndege.

(Swahili)

7-airfield SM7-PRS-land-FV 9.aeroplane

'An aeroplane has landed on the airfield (so the airfield is in use again).'

(Whiteley \& Mganga 1969, Whiteley 1972, Russell 1985) 
The examples show the range of pragmatic effects associated with inversion constructions, ranging from exclusive and contrastive focus on the logical subject to presentational and thetic interpretations. In our analysis, all these effects result from the same underlying structural dynamics. Pragmatic focus effects are associated with the late placement of the logical subject, and are related to the particular context of use. In inversion constructions, the late placed logical subject provides a value for an incomplete proposition, which serves as the context against which the logical subject is interpreted. ${ }^{16}$ The DS analysis developed here does not assign a focus feature to the logical subject, nor does it assume that it resides in some designated focus position (neither of these options is expressible in the system). Rather, the analysis claims that hearers are asked to make certain parsing choices, and these choices, in conjunction with the context in which the utterance is parsed, give rise to pragmatic effects and allow the hearer to derive additional, contextual meaning over and above the proposition expressed (see Sperber \& Wilson 1995, Marten 2007, Kempson, Kiaer \& Cann 2009). Differences between focus readings result from the terms and predicates involved, and from the wider context. For example, that presentational focus is more easily found with locative inversion than with patient or instrument inversion (at least in

\footnotetext{
${ }^{16}$ This contrasts with right-peripheral background topics, which are also 'late' but which merely confirm the independently established interpretation of a preceding pronominal expression (see Marten 2011):
}
(i) V-è-yá,
òvà-éndà.
(Otjiherero)

\section{SM2-PST-come 2-visitor}

'They came, the visitors (that is).'

(Marten 2011: 801) 
the available descriptions) may reflect the fact that locations are more easily conceptualised as backgrounds than instruments or patients.

Against this general background of the DS analysis of structure building and contextual effects, the particular case of inversion constructions shows, in fact, a structural parallel with analyses which assume that focus results from consideration of alternatives (e.g. Lambrecht 1994, Rooth 1996, Bearth 1999, Krifka 2007). Through the late placement of the subject, there is a stage in the derivation where an incomplete proposition has been established, and the last remaining value is supplied by the postverbal logical subject, analogous to the representation of alternatives as propositional frames with a value abstracted. The particular structure building operations allow the hearer to construct a complex context against which a final term is evaluated.

\subsection{Sources of cross-linguistic variation}

A final question we address relates to cross-linguistic variation. As shown in Section 2, there is considerable variation with respect to the distribution of inversion constructions across the Bantu family. Given our uniform analysis, which assigns all inversion constructions the same structure, we have to explain why not all inversion constructions are found in all Bantu languages. There are three sources of variation in our analysis (see Marten \& van der Wal 2014): the coding of locatives, the coding of preverbal NPs, and thematic restrictions. The first two factors are independent of inversion constructions as such, but have an effect on their distribution, while the last factor is centrally related to the nature of inversion constructions. 
The coding of locatives has already been mentioned. It refers to a typological difference between those Bantu languages in which locative morphology is noun class morphology and locative phrases are noun phrases, and on the other hand, those in which locative morphology has become prepositional and locatives are prepositional phrases. The latter development - the so-called 'great siSwati locative shift' (Marten 2010) - has a number of repercussions, including the loss of locative noun classes in both nominal and verbal morphology, use of new nominal locative morphology, the development of a locative subject marker as an expletive subject marker, demonstratives intervening between the locative marker and the nominal stem, agreement with only the original noun in modified locative phrases, no locative object marker, special relative marking strategy for locatives, as well as the absence of formal locative inversion (Marten 2010: 264). The cross-linguistic (near) complementarity of formal and semantic locative inversion (Marten \& van der Wal 2014) confirms the hypotheses that the two are the same construction and only seemingly different due to the independent differences in the locative system (Buell 2007). There might of course be differences in terms of usage. In formal locative inversion, the initial phrase is clearly marked as a location (for example, 'at the house'), while in semantic locative inversion, the locative ('the house') could also be a patient, or an instrument, or indeed an agent. We would thus expect that semantic locative inversion might be more sensitive to the context, more restrictive with respect to predicates, and probably less frequent and less versatile in the terms of construction. However, this requires further research.

The second typological difference which affects inversion constructions is the difference between Bantu languages in which the preverbal NP can be a subject, and 
agreement is grammatical agreement, and those in which the preverbal NP is a syntactic topic and agreement is anaphoric agreement (e.g. Bresnan \& Mchombo 1989, Zerbian 2006). In DS terms, the difference resides in the lexical specification of the subject marker, which does or does not allow local update through the operation Merge. If it does, an initial unfixed node can merge with the locally unfixed node of the subject marker. If it does not, initial NPs have to annotate a Link structure, and the identity of semantic content is achieved through the anaphoric copying of the formula value of the Link structure (Marten 2011). As noted in Section 3, several previous analyses have tried to relate the distribution of inversion constructions to the difference between subject and topic, but this is not confirmed by a larger set of comparative data. Since the preverbal NP in inversion constructions is often topical, the question of whether it is coded as a syntactic topic or as a syntactic subject (which can still be topical) is important for the analysis of inversion constructions, and will determine a range of properties of inversion constructions in different languages. However, in our approach this is related to, but strictly speaking independent of, the analysis of inversion constructions.

The final source of variation is what accounts for the cross-linguistic distribution of inversion constructions across Bantu, namely the thematic restrictions operative in different languages. Thematic restrictions have already been proposed to play a role in variation in locative inversion, with different languages licensing locative inversion only if the remaining argument is a theme, or only if agent and theme do not co-occur, etc. (Demuth \& Mmusi 1997, Khumalo 2010). As noted in Section 3, from the crosslinguistic distribution of Bantu inversion constructions it appears that the relevant thematic distinctions are location, instrument and patient (disregarding complement 
inversion for which there are very few data), and that there is a partial hierarchical order locative $<$ instrument and locative $<$ patient, with no strict order between instrument and patient. Thematic restrictions have been argued to be relevant in other domains of grammar, such as applicatives, and two proposals about hierarchical orders of thematic roles are given in (52) and (53) (see Wald 1997 for discussion):

(52) Agent $>$ Beneficiary $>$ Goal/Recipient/Experiencer $>$ Instrument $>$ Patient/Theme Locative

(Bresnan \& Kanerva 1989: 23)

(53) Agent $>$ Beneficiary $>$ Goal/Recipient/Experiencer $>$ Patient/Theme $>$ Instrument $>$ Locative

(Hawkinson \& Hyman 1974: 159; Trithart 1977: 21)

Both hierarchies place locative at the bottom of the scale, but differ with regard to the position of instrument and patient, precisely the roles which are only partly ordered in our analysis. The order of the roles reflects, in part, decreasing topic-worthiness (Givón 1979, Hopper \& Thompson 1980, Lambrecht 1994), and so the markedness of inversion constructions results from the mismatch between the coding of the preverbal NP as topic and its inherent low topic-worthiness. Since the postverbal NP expresses the agent, the greater difference in topic-worthiness between agent and locative might be responsible for the more widespread use of locative inversion than other inversion types, as well as for the differences in syntactic restrictions between inversion types 
which has sometimes been noted - for example the absence of ditransitive predicates in patient inversion (Kimenyi 1980). ${ }^{17}$

Next to thematic restrictions, a number of other semantic constraints on inversion constructions have been noted in the literature. Russell (1985) provides a more finegrained classification of Swahili verbs undergoing patient inversion, distinguishing four types of predicates, which differ in the degree of contrast between the two arguments, and the degree of focus associated with the construction. The role of animacy in patient inversion has been noted by Kimenyi (1980) for Kinyarwanda, Barrett-Keach (1980) for Swahili, and Sabimana (1986) for Kirundi (see also Morimoto 2000: 115). Typically, patient inversion is only possible if the referent of the logical subject is more animate than the logical object, or human. However, Kimenyi (1988) notes that in Kinyarwanda even two human arguments are possible, for example, with predicates like -vuur- 'cure' since it is culturally known that doctors cure patients. A similar point is made by Whiteley \& Mganga (1969), who propose that the meaning of inversion constructions includes a marked state of affairs, in the context of culturally mediated expectations, and introduce the term 'contra-experiential' for this meaning. Another aspect of patient inversion is found with bivalent predicates (Russell 1985) in Swahili and Kirundi, which include meanings like 'enter', 'permeate' and 'seep', where the two arguments can be analysed as conforming to a container/contained image schema (Gibson 2008).

Overall, three aspects contribute to the interpretation of inversion constructions and give rise to the variation in the cross-linguistic distribution: parameterised thematic

\footnotetext{
${ }^{17}$ Although further empirical work may reveal a more fine-grained picture, similar to the development of our understanding of restrictions on locative inversion (e.g. from Bresnan \& Kanerva 1989 to Khumalo 2010).
} 
restrictions on the arguments projected in preverbal position, more fine-grained lexical constraints relating, for example, to animacy or the lexical semantics of the predicate involved, and the context in which the inversion construction is used, which may include the wider cultural context, as noted by Kimenyi (1988), as well as the local, immediate context, as pointed out by Whiteley \& Mganga (1969).

We will not attempt a more detailed formalisation of these interpretative differences or their role in giving rise to variation. From a DS perspective the pragmatic effects are a reflex of the analysis proposed (see Section 5.3 above). Given the strong lexical base of the framework, lexical variation, in particular with respect to the semantics of the predicates involved, can be modelled as part of lexical entries of the relevant verbs. The most challenging issue is whether the thematic relations which play a role in inversion constructions can also be reduced to lexical information, or whether they have to be stated independently. This is a challenge for any lexicalist framework, and further work is needed to address this question in more detail. ${ }^{18}$

\subsection{Summary}

In this section, we have developed an analysis of Bantu inversion constructions which assigns them a uniform structural analysis, formalised within Dynamic Syntax. At its core is the observation that in all inversion constructions the information introduced by the initial phrase is interpreted only after the verb has been parsed, and as an argument of the predicate introduced by the verb. As a result of the tree logic which determines

\footnotetext{
${ }^{18}$ In LFG, where different levels of representation are assumed, this would appear to be easier to express, as argued to be the case for locative inversion in Bresnan \& Kanerva's (1989) early work.
} 
tree relations in DS, the presence of a locally unfixed node during the structure building process debars the presence of another locally unfixed node until the verb has been parsed. One of the central structural qualities of all inversion constructions - absence of object marking - is therefore naturally precluded by the analysis. Our account also addresses the pragmatic effects found with inversion constructions. The initial phrase can be construed as a Link structure or as an unfixed node - providing structural representations of pragmatic topichood. The postverbal phrase is encountered late, and through this late placement, pragmatic effects are licensed which encompass both term focus, such as new information or exclusive focus, and presentational and thetic readings. Different readings result from the distinct lexical information provided by the predicate and its arguments, as well as from the interaction with the relevant context.

The analysis in itself does not address cross-Bantu variation in inversion constructions. For this, we have proposed, in Section 5.4, a thematic hierarchy with language-specific restrictions on which inversion types are licensed. Cross-linguistic evidence indicates that the hierarchy is partially ordered, with the presence of either patient inversion or instrument inversion implying the presence of locative inversion.

Before bringing out some wider conclusions of the analysis, in the next section we briefly discuss the relevance of the analysis for passives.

\section{PASSIVES}

Early analyses of inversion constructions have pointed out parallels between inversion and passives (as noted in Section 3). This similarity is confirmed by our analysis, which is easily extendable to passives. However, one difference is that object marking is possible in passives in some Bantu languages. The analysis would thus need to be 
modified to accommodate those cases. Leaving the specific details of this to future work, in the current section we discuss how the analysis could be extended to passive constructions more broadly.

There are three main parallels between inversion constructions and passives: the preverbal phrase expresses a role other than the logical subject, object marking is disallowed (in some Bantu languages), and the preverbal phrase is often topical and the postverbal NP (if expressed) is often focal.

The first two points can be seen in the following examples from Otjiherero. In (54) the two non-agents òvánátjè 'children' (the benefactive argument) and òmbápírà 'letter' (the theme argument) are found in the preverbal position and trigger agreement on the verb.

(54) (a) Òvà-nátjè v-á-tjàng-ér-w-á

òmbápírà. (Otjiherero)

2-children SM2-PST-write-APPL-PASS-FV 9.letter

'The children were written a letter.'

(b) Òmbàpírà y-á-tjàng-ér-w-á òvá-nátjè.

9.letter SM9-PST-write-APPL-PASS-FV 2-children

'A letter was written to/for the children.' 
Furthermore, as shown in (55), neither of the remaining postverbal NPs can be object marked, irrespective of their thematic role or grammatical function.

(55) (a) *Òvá-nátjè v-é-ì-tjàng-ér-w-á

2-children SM2-PST-OM9-write-APPL-PASS-FV

Intended: 'The children were written it'

(b) *Òmbàpírà y-é-và-tjàng-ér-w-á

9.letter SM9-PST-OM2-write-APPL-PASS-FV

Intended: 'The letter was written to/for them'

(Marten, field notes)

However, as noted above, there are Bantu languages which do allow object marking in passives, such as siSwati or Kinyarwanda (see Woolford 1995):

(56) Sínínì sí-wù-ník-w-è
7.friend ngù Jôhn.
'The friend was given it by Jôhn.'

(Woolford 1995: 201, from De Guzman 1987)

Thus, the parallel with inversion constructions only obtains for a subset of Bantu languages.

The third parallel, relating to information structure, is that preverbal NPs in passives are often topical (see Siewierska 1984), while postverbal agents can be focal. In many 
Bantu languages, subjects cannot be questioned (or focused) in-situ, and subject questions take either the form of a cleft, or an inversion construction (see e.g. Zerbian 2006). However, another alternative is the use of a passive construction where the logical subject is expressed by a prepositional phrase, and is questioned/focused, for example in Sesotho (Demuth 1989, Demuth \& Kline 2006):
(a) Li-jo li-pheh-iloe ke mang? (Sesotho)
5-food SM5-cook-PRF.PASS by who
'The food was cooked by who?'
(b) Li-pheh-iloe ke Thabo.
SM5-cook-PRF.PASS by Thabo
'It was cooked by Thabo.'

(Demuth 1989: 68)

The information structure of these examples comes quite close to the information structure of inversion constructions as discussed above.

A final observation regarding the parallelism of passives and inversion constructions comes from languages such as Haya (Duranti \& Byarushengo 1977) and Luganda (Ashton et al. 1954, Pak 2008), where the agent NP in a passive construction is not marked by a preposition and precedes other postverbal arguments:
(58) Omu-kazi y-a-w-ebw' omu-sajja eki-tabo. (Luganda)
1-woman SM1-PST-give-PASS 1-man 7-book

'The woman was given the book by the man.' 
(Pak 2008: 365)

The construction combines verbal passive morphology with a coding of the agent similar to inversion constructions (although the agent in Luganda passives is optional).

Following previous DS analyses of passives (Cann 2011, Wu 2011), the parallelism between inversion and passive constructions in terms of our analysis is expressed as follows. In both cases we assume that an initial phrase annotates a Link structure or an unfixed node, and that the subject marker licenses the building of a locally unfixed node. The locally unfixed node is merged in object position once the verb is parsed. So far, there is no difference in the steps of the relevant derivations. However, in passives, the verb is followed by a passive marker such as $-w$ in Swahili:

(59) Ki-kombe ki-li-vunj-w-a.

(Swahili)

7-cup SM7-PST-break-PASS-FV

'The cup was broken.'

Due to the presence of the passive marker, no postverbal agent needs to be expressed, and so we propose that the subject annotation is provided by the passive marker. The relevant snapshot of the derivation is shown in (60). 
(60) Ki-kombe ki-li-vunj-w-a.

7-cup SM7-PST-break-PASS-FV

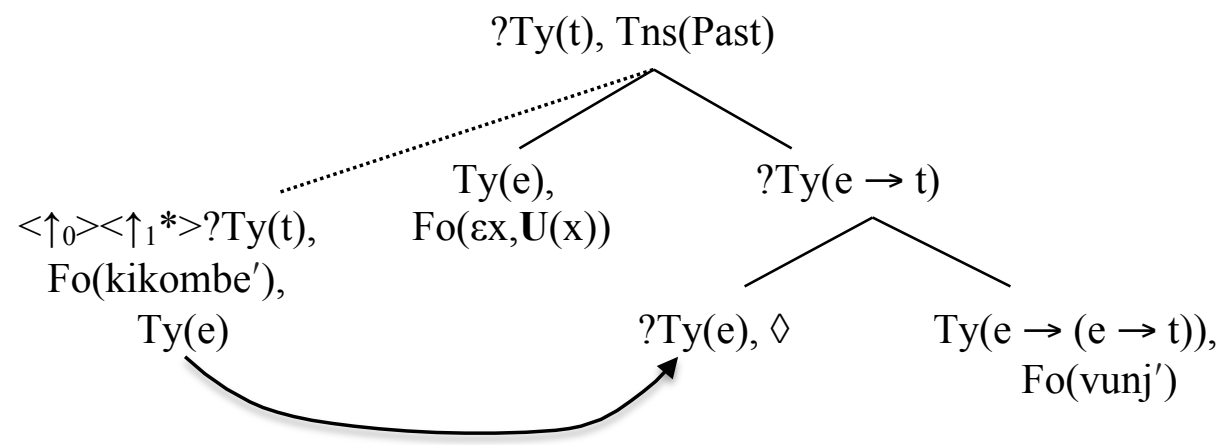

The subject is annotated with a metavariable place holder $(\varepsilon x, \mathbf{U}(\mathrm{x}))$ which is enriched through the semantics of the predicates (e.g. as 'breaker' in the case of vunja 'break') and can be further specified by lexical information from an optional 'by'-phrase (which we assume can be added through a Link structure) (see Cann 2011: 298). A possible lexical entry for the passive marker is as follows:

$$
\begin{aligned}
& \text { IF } \quad \text { Ty }(e \rightarrow(e \rightarrow t)) \\
& \text { THEN } \operatorname{go}\left(<\uparrow_{1}>\right), \operatorname{go}\left(<\uparrow_{1}>\right), \operatorname{go}\left(<\downarrow_{0}>\right), \\
& -w- \\
& \operatorname{put}(\operatorname{Ty}(\mathrm{e}), \operatorname{Fo}(\varepsilon x, \mathbf{U}(\mathrm{x}))), \operatorname{go}(<\uparrow>), \\
& \mathrm{go}\left(<\downarrow_{1}>\right), \mathrm{go}\left(<\downarrow_{0}>\right) \\
& \text { ELSE abort }
\end{aligned}
$$

The passive marker as modelled in (61) is parsed after the predicate has been annotated and then moves the pointer up the tree to the subject position, provides a pronominal metavariable annotation, and then moves the pointer to the object node. Since lexical information from the passive marker provides an annotation of the subject node and 
fulfils the requirement for a Ty(e) expression, the tree can be completed without further input, and so in passives no postverbal subject is necessary.

As noted at the outset of the section, a number of parallels between passives and inversion constructions can be accounted for by the DS analysis developed here. However, typological differences in object marking with passives - which is possible in some Bantu languages, but not in others - require a modification of the analysis which we will leave for a future occasion. ${ }^{19}$

\section{CONCLUSIONS}

In this paper we have developed an analysis of Bantu inversion constructions which highlights their structural and interpretative similarities. We have proposed a uniform analysis based on Dynamic Syntax which addresses key qualities of the construction. Cross-linguistic variation in the distribution of inversion constructions has then been related to a partially ordered hierarchy of thematic roles. We have also shown how the analysis can be extended to passives, and have noted that the availability of object marking in some Bantu passives would require some modification of the analysis.

19 A potential DS analysis might explore a more fine-grained typology of object markers, following proposals by Woolford (1995) and Zeller (2012b). Some object markers may then be analysed as decorating a Link structure, or as projecting a complex annotation on one node, explaining co-occurrence restrictions on object marking found in different Bantu languages (see Marten \& Kula 2012), and these might be projected in anticipation of the passive marker and subsequently licensed by it (see Gibson 2012 for an analysis of some tense markers along these lines). 
There are two aspects of the analysis which are worth addressing as part of the conclusion and as areas for further research: the importance of thematic roles and grammatical functions, and the role of left-to-right processing for inversion constructions.

Thematic roles have turned out to be central for our analysis of cross-linguistic variation in Bantu inversion constructions. We have also noted the possibility of relating thematic restrictions to other semantic restrictions on predicates taking part in inversion constructions, and the context dependence of acceptable inversions. We believe that this is an important area for future research, as it relates to wider discussion about the nature of thematic relations in grammar, and the relation between grammatically relevant thematic hierarchies and the effect of specific lexical information about semantic subcategorisation, for which Bantu inversion constructions provide extensive evidence.

Thematic roles are often conceptualised in relation to grammatical functions. However, in our DS analysis, we have not employed primitive notions of grammatical functions, even though it resembles grammatical function-changing analyses in that the initially parsed NP is interpreted in the (logical) object position. The analysis has made reference to logical subjects and objects: Tree positions indicate predicate-argument structure, and so can be used to identify logical subjects and objects. On the other hand, Link structures, unfixed nodes, and locally unfixed nodes are simply structural devices of tree growth. The absence of grammatical functions, together with the structural options of Link structures and unfixed nodes at the outset of the parse, have allowed us to refer to topic/subject effects at the left periphery without making these part of the formal explanation of inversion constructions as such, and so keeping cross-linguistic 
variation in the two domains apart. Similarly, our sketch of an analysis of passives was formulated without recourse to grammatical functions (see Cann 2011). Inversion and passive constructions can be thought of as central examples for the use of grammatical functions, but the DS analysis developed here raises the question whether the notion of grammatical function could be replaced by dynamic concepts of structure building.

Finally, our analysis is compatible with a more functional view of inversion constructions, relating to differences in markedness and relative differences in topicworthiness between the two arguments of the construction. Formal locative inversion is more common across Bantu and is more explicitly marked (by locative morphology) than other inversion constructions. Furthermore, the semantic/thematic difference between locatives and agents in locative inversion is greater than the difference between patients and agents in patient inversion, and between instruments and agents in instrument inversion. From a DS perspective, it would be interesting to explore whether in language comprehension the initial NP in (formal and semantic) locative inversion is easier to parse correctly (as not being the agent) than the initial NP in patient or instrument inversion. This would allow us to compare the different effects of formal marking and thematic distance, and would provide more parsing-based evidence for variation in inversion constructions.

In summary, we have provided a formal analysis of inversion constructions in Bantu, based on comparative evidence, which addresses invariant qualities of the construction type in terms of morphosyntactic structure and information structural and pragmatic effects, as well as variation in cross-linguistic distribution. However, we have also noted a number of outstanding issues in terms of available data and extension of the analysis, which we hope will be taken up in future research. 


\section{REFERENCES}

Ashton, E. O., E. M. K. Mulira, E. G. M. Ndawula \& A. N. Tucker. 1954. A Luganda grammar. London: Longmans, Green \& Co.

Barrett-Keach, Camillia. 1980. The syntax and interpretation of the relative clause construction in Swahili. Ph.D. dissertation, University of Massachusetts.

Bearth, Thomas. 1999. The contribution of African linguistics towards a general theory of focus: Update and critical review. Journal of African Languages and Linguistics $20,121-156$.

Blackburn, Patrick \& Wilfried Meyer-Viol. 1994. Linguistics, logic and finite trees. Bulletin of the Interest Group for Pure and Applied Logic 2, 3-29.

Bokamba, Eyamba Georges. 1976. Question formation in some Bantu languages. Ph.D. dissertation, Indiana University.

Bokamba, Eyamba Georges. 1979. Inversion as grammatical relation changing rules in Bantu. Studies in the Linguistic Sciences 9.2, 1-24.

Bokamba, Eyamba Georges. 1985. Verbal agreement as a noncyclic rule in Bantu. In Goyvaerts (ed.), 9-54.

Bostoen, Koen \& Léon Mundeke. 2011. Passiveness and inversion in Mbuun (Bantu B87, DRC). Studies in Language 35.1, 72-111.

Bostoen, Koen \& Léon Mundeke. 2012. Subject marking, object-verb order and focus in Mbuun (Bantu, B87). Southern African Linguistics and Applied Language Studies $30.2,139-154$.

Bouzouita, Miriam. 2009. The diachronic development of Spanish clitic placement. Ph.D. dissertation, King's College London.

Bowers, John. 1993. The syntax of predication. Linguistic Inquiry 24.4, 591-656. 
Bresnan, Joan \& Jonni M. Kanerva. 1989. Locative inversion in Chichewa: A case study of factorization in grammar. Linguistic Inquiry 20, 1-50.

Bresnan, Joan \& Sam A. Mchombo. 1987. Topic, pronoun, and agreement in Chichewa. Language 63, 741-782.

Buell, Leston. 2007. Semantic and formal locatives: Implications for the Bantu locative inversion typology. SOAS Working Papers in Linguistics 15, 105-120.

Cann, Ronnie. 2011. Towards an account of the English auxiliary system. In Kempson et al. (eds.), 273-310.

Cann, Ronnie, Ruth Kempson \& Lutz Marten. 2005. The dynamics of language: An introduction (Syntax and Semantics 35). Oxford: Elsevier.

Carstens, Vicki. 2005. Agree and EPP in Bantu. Natural Language \& Linguistic Theory 23, 219-279.

Carstens, Vicki. 2011. Hyperactivity and hyperagreement in Bantu. Lingua 121, 721741.

Creissels, Denis. 2011. Tswana locatives and their status in the inversion construction. Africana Linguistica 17, 33-52.

De Guzman, Videa P. 1987. Indirect objects in SiSwati. Studies in African Linguistics $18,309-325$.

Demuth, Katherine. 1989. Maturation and the acquisition of the Sesotho passive. Language 65.1, 56-80.

Demuth, Katherine. 1990. Subject, topic and Sesotho passive. Journal of Child Language 17, 67-84.

Demuth, Katherine \& Carolyn Harford. 1999. Verb raising and subject inversion in comparative Bantu. Journal of African Languages and Linguistics 20.1, 41-61. 
Demuth, Katherine \& Melissa Kline. 2006. The distribution of passives in spoken Sesotho. Southern African Linguistics and Applied Language Studies 24, 377-388.

Demuth, Katherine \& Sheila Mmusi. 1997. Presentational focus and thematic structure in comparative Bantu. Journal of African Languages and Linguistics 18, 1-19.

Diercks, Michael. 2011. The morphosyntax of Lubukusu locative inversion and the parameterization of Agree. Lingua 121, 702-720.

Diercks, Michael. 2012. Parameterizing Case: Evidence from Bantu. Syntax 15.3, $253-$ 286.

Duranti, Alessandro \& Ernest Rugwa Byarushengo. 1977. On the notion of 'Direct Object'. In Ernest Rugwa Byarushengo, Alessandro Duranti \& Larry M. Hyman (eds.), Haya grammatical structure, 45-71. Los Angeles, CA: Department of Linguistics, University of Southern California.

É. Kiss, Katalin. 1998. Identificational focus versus information focus. Language 74.2, $245-273$.

Gibson, Hannah. 2008. Half empty or half full: An analysis of subject-object inversion in Swahili. MA dissertation, SOAS, University of London.

Gibson, Hannah. 2012. Auxiliary placement in Rangi: A Dynamic Syntax perspective. Ph.D. dissertation, SOAS, University of London.

Gibson, Hannah \& Lutz Marten. 2015. Variation and grammaticalisation in Bantu complex verbal constructions: The dynamics of information growth in Swahili, Rangi and siSwati. To appear in Léa Nash \& Pollet Samvelian (eds.), Approaches to complex predicates. Leiden: Brill.

Givón, Talmy. 1979. On understanding grammar. New York: Academic Press. 
Goyvaerts, Didier L. (ed.). 1985. African linguistics: Essays in memory of M. W. K. Semikenke. Amsterdam: Benjamins.

Halliday, M. A. K. 1967. Notes on transitivity and theme in English: Part 2. Journal of Linguistics 3, 199-244.

Hamlaoui, Fatima \& Emmanuel-Moselly Makasso. 2013. Object left-dislocation, topicalization and the syntax-phonology mapping of intonation phrases in Bàsàá. Presented at Bantu5, Paris.

Hamlaoui, Fatima \& Emmanuel-Moselly Makasso. 2015. Focus marking and the unavailability of inversion structures in the Bantu language Bàsàá (A43). Lingua 154, $35-64$.

Hawkinson, Annie \& Larry M. Hyman. 1974. Hierarchies of natural topic in Shona. Studies in African Linguistics 5, 147-170.

Henderson, Brent. 2006. The syntax and typology of Bantu relative clauses. Ph.D. dissertation, University of Illinois at Urbana-Champaign.

Henderson, Brent. 2011. Agreement, locality, and OVS in Bantu. Lingua 121, 742-753.

Hopper, Paul J. \& Sandra A. Thompson. 1980. Transitivity in grammar and discourse. Language 56.2, 251-299.

Julien, Marit. 2000. Syntactic heads and word formation. Oxford: Oxford University Press.

Kavari, Jekura U., Lutz Marten \& Jenneke van der Wal. 2012. Tone cases in Otjiherero: Head-complement relations, linear order and information structure. Africana Linguistica 18, 315-353. 
Kempson, Ruth, Ronnie Cann \& Lutz Marten. 2013. Tree growth dynamics. In Cristiano Chesi (ed.), Directionality of Phrase Structure Building: Special issue of STIL Studies in Linguistics 6, 49-81.

Kempson, Ruth, Eleni Gregoromichelaki \& Christine Howes (eds.). 2011. The dynamics of lexical interfaces. Stanford, CA: CSLI Publications.

Kempson, Ruth, Jieun Kiaer \& Ronnie Cann. 2009. Periphery effects and the dynamics of tree growth. In Benjamin Shaer, Philippa Cook, Werner Frey \& Claudia Maienborn (eds.), Dislocated elements in discourse: Syntactic, semantic, and pragmatic perspectives, 141-172. New York: Routledge.

Kempson, Ruth, Wilfried Meyer-Viol \& Dov Gabbay. 2001. Dynamic Syntax. Oxford: Blackwell.

Khumalo, Langa. 2010. Passive, locative inversion in Ndebele and the unaccusative hypothesis. South African Journal of African Languages 30.1, 22-34.

Kimenyi, Alexandre. 1980. A relational grammar of Kinyarwanda. Berkeley, CA: University of California Press.

Kimenyi, Alexandre. 1988. Passives in Kinyarwanda. In Masayoshi Shibatani (ed.), Passive and voice, 355-386. Amsterdam: Benjamins.

Kinyalolo, Kasangati Kikuni Wabongambilu. 1991. Syntactic dependencies and the SPEC-head Agreement Hypothesis in KiLega. Ph.D. dissertation, University of California, Los Angeles.

Krifka, Manfred. 2007. Basic notions of information structure. In Caroline Féry, Gisbert Fanselow \& Manfred Krifka (eds.), Working papers of the SFB 632: Interdisciplinary Studies on Information Structure (ISIS), 13-55. Potsdam: Universitätsverlag Potsdam. 
Lambrecht, Knud. 1994. Information structure and sentence form. Cambridge: Cambridge University Press.

Marten, Lutz. 2002. At the syntax-pragmatics interface: Verbal underspecification and concept formation in Dynamic Syntax. Oxford: Oxford University Press.

Marten, Lutz. 2006. Locative inversion in Herero: More on morphosyntactic variation in Bantu. ZAS Papers in Linguistics 43, 97-122.

Marten, Lutz. 2007. Focus strategies and the incremental development of semantic representations: Evidence from Bantu. In Enoch Aboh, Katharina Hartmann \& Malte Zimmermann (eds.), Focus strategies in African languages: The interaction of focus and grammar in Niger-Congo and Afro-Asiatic, 113-135. Berlin \& New York: Mouton de Gruyter.

Marten, Lutz. 2010. The great siSwati locative shift. In Anne Breitbarth, Christopher Lucas, Sheila Watts \& David Willis (eds.), Continuity and change in grammar, 249267. Amsterdam: John Benjamins.

Marten, Lutz. 2011. Information structure and agreement: Subjects and subject markers in Swahili and Herero. Lingua 121, 787-804.

Marten, Lutz. 2014. The preverbal position(s) in Bantu inversion constructions: Theoretical and comparative considerations. ZAS Papers in Linguistics 57, 136-159. Marten, Lutz, Ruth Kempson \& Miriam Bouzouita. 2008. Concepts of structural underspecification in Bantu and Romance. In Cécile de Cat \& Katherine Demuth (eds.), The Romance-Bantu connection, 3-39. Amsterdam: John Benjamins.

Marten, Lutz \& Nancy C. Kula. 2012. Object marking and morphosyntactic variation in Bantu. Southern African Linguistics and Applied Language Studies 30.2, 237-253. 
Marten, Lutz, Nancy C. Kula \& Nhlanhla Thwala. 2007. Parameters of morphosyntactic variation in Bantu. Transactions of the Philological Society 105, 253-338.

Marten, Lutz \& Deograsia Ramadhani. 2001. An overview of object marking in Kiluguru. SOAS Working Papers in Linguistics and Phonetics 11, 259-275.

Marten, Lutz \& Jenneke van der Wal. 2014. A typology of Bantu subject inversion. Linguistic Variation 14.2, 317-368.Matić, Dejan \& Daniel Wedgwood. 2013. The meaning of focus: The significance of an interpretation-based category in crosslinguistic analysis. Journal of Linguistics 49, 127-163.

Mkude, Daniel J. 1974. A study of Kiluguru syntax with special reference to the transformational history of sentences with permuted subject and object. Ph.D. dissertation, SOAS, University of London.

Möhlig, Wilhelm J. G., Lutz Marten \& Jekura U. Kavari. 2002. A grammatical sketch of Herero. Cologne: Köppe.

Morimoto, Yukiko. 2000. Discourse configurationality in Bantu morphosyntax. Ph.D. dissertation, Stanford University.

Morimoto, Yukiko. 2006. Agreement properties and word order in comparative Bantu. ZAS Papers in Linguistics 43, 161-187.

Ndayiragije, Juvénal. 1999. Checking economy. Linguistic Inquiry 30, 399-444. Pak, Marjorie. 2008. A-movement and intervention effects in Luganda. In Natasha Abner \& Jason Bishop (eds.), 27th West Coast Conference on Formal Linguistics (WCCFL27), 361-369. Sommerville, MA: Cascadilla Proceedings Project.

Petzell, Malin. 2008. The Kagulu language of Tanzania: Grammar, texts and vocabulary. Cologne: Köppe. 
Riedel, Kristina. 2009. The syntax of object marking in Sambaa: A comparative Bantu perspective. Ph.D. dissertation, University of Leiden.

Riedel, Kristina \& Lutz Marten. 2012. Locative object marking and the argumentadjunct distinction. Southern African Linguistics and Applied Language Studies 30.2., $277-292$.

Rooth, Mats. 1996. Focus. In Shalom Lappin (ed.), The handbook of contemporary semantic theory, 271-297. Oxford: Blackwell.

Russell, Joan. 1985. Swahili quasi-passives: The question of context. In Goyvaerts (ed.), 477-490.

Sabimana, Firmard. 1986. The relationship structure of the Kirundi verb. Ph.D. dissertation, Indiana University.

Salzmann, Martin. 2011. Towards a typology of locative inversion - Bantu, perhaps Chinese and English - but beyond? Language and Linguistics Compass 5.4, 169-189.

Sasse, Hans-Jürgen. 2006. Theticity. In Giuliano Bernini \& Marcia L. Schwartz (eds.), Pragmatic organization of discourse in the languages of Europe, 255-308. Berlin \& New York: Mouton de Gruyter.

Siewierska, Anna. 1984. The passive: A comparative linguistic analysis. London: Croom Helm.

Sperber, Dan \& Deirdre Wilson. 1995. Relevance: Communication and cognition, 2nd edn. Oxford: Blackwell.

Trithart, Mary Lee. 1977. Relational grammar and Chichewa subjectivization. MA dissertation, University of California, Los Angeles.

Ura, Hiroyuki. 2000. Checking theory and grammatical functions in Universal Grammar. Oxford: Oxford University Press. 
Vallduví, Enric. 1992. The informational component. New York: Garland.

Visser, Marianna. 1989. The syntax of the infinitive in Xhosa. South African Journal of African Languages 9.4., 154-185.

Wald, Benji. 1997. Instrumental objects in the history of topicality and transitivity in Bantu. In Rose-Marie Déchaine \& Victor Manfredi (eds.), Object positions in BenueKwa, 221-253. The Hague: Holland Academic Graphics.

Whiteley, Wilfred Howell. 1972. Case complexes in Swahili. Studies in African Linguistics 3.1, 1-45.

Whiteley, Wilfred Howell \& J. D. Mganga. 1969. Focus and entailment: Further problems of transitivity in Swahili. African Language Review 8, 108-25.

Woolford, Ellen. 1995. Why passive can block object marking. In Akinbiyi Akinlabi (ed.), Theoretical approaches to African linguistics, 199-215. Trenton, NJ: Africa World Press.

Wu, Yicheng. 2011. Towards a dynamic typology of passives. In Kempson et al. (eds.), $131-162$.

Zeller, Jochen. 2012a. Instrument inversion in Zulu. In Michael R. Marlo, Nikki B. Adams, Christopher R. Green, Michelle Morrison \& Tristan M. Purvis (eds.), 42nd Annual Conference on African Linguistics, 134-148. Somerville, MA: Cascadilla Proceedings Project.

Zeller, Jochen. 2012b. Object marking in isiZulu. Southern African Linguistics and Applied Language Studies 30.2, 219-235.

Zeller, Jochen. 2013. Locative inversion in Bantu and predication. Linguistics 51.6, $1107-1146$. 
Zerbian, Sabine. 2006. Expression of information structure in the Bantu language Northern Sotho (ZAS Papers in Linguistics 45). Berlin: ZAS.

Authors' addresses: (Marten)

Faculty of Languages and Cultures, SOAS, University of London, Thornhaugh Street, Russell Square, London WC1H 0XG, UK lm5@soas.ac.uk

(Gibson)

Department of Linguistics, SOAS, University of London, Thornhaugh Street, Russell Square, London WC1H OXG, UK hg6@soas.ac.uk 